\title{
Leonotis Nepetifolia Mediated Eco-Friendly Synthesis of Zno Nps: Photocatalytic, Antioxidant Activities and Their Applications to Nano- Composite Electrode Material for Supercapacitor
}

Gajendran Pavithra ( $\sim$ pavithragajendran10@gmail.com )

School of Advanced Sciences VIT https://orcid.org/0000-0002-8081-0868

Santhakumar kannappan

School of Advanced Sciences VIT

\section{Research Article}

Keywords: Green synthesis, Zinc oxide nanoparticles (ZnO NPs), L. nepetifolia flower extract, photocatalytic activity, antioxidant activity, and electrochemical analysis.

Posted Date: June 14th, 2021

DOl: https://doi.org/10.21203/rs.3.rs-602808/v1

License: (c) (1) This work is licensed under a Creative Commons Attribution 4.0 International License. Read Full License 


\title{
LEONOTIS NEPETIFOLIA MEDIATED ECO-FRIENDLY SYNTHESIS OF ZnO NPs: PHOTOCATALYTIC, ANTIOXIDANT ACTIVITIES AND THEIR APPLICATIONS TO NANO-COMPOSITE ELECTRODE MATERIAL FOR SUPERCAPACITOR
}

\author{
G. Pavithra ${ }^{a}$, K. Santhakumar ${ }^{a, *}$ \\ a Department of Chemistry, School of Advanced Sciences \\ VIT, Vellore 632014, Tamil Nadu, India.
}

*Corresponding author information

K. Santhakumar

Email: ksanthakumar@vit.ac.in

Disclosures: The investigators don't possess any conflict of interest concerning the current manuscript.

\begin{abstract}
The present paper describes the green synthesis of Zinc oxide nanoparticles (ZnO NPs) from the flowers of L. nepetifolia. The synthesis of $\mathrm{ZnO}$ nanoparticles and examined by using Ultraviolet-visible spectroscopy, Fourier Transform-Infrared spectroscopy, X-ray Diffraction analysis, Dynamic Light Scattering analysis, Raman spectroscopy, Scanning Electron Microscopy and Energy Dispersive X-ray spectroscopy, Transmission Electron Microscopy, and Thermogravimetric Analysis. The photocatalytic studies were followed using methylene blue (MB) dye by $\mathrm{ZnO}$ nanoparticles by using sunlight as a source. The degradation of MB dye is found to be $90 \%$. Then the synthesized $\mathrm{ZnO}$ nanoparticles help to evaluate the antioxidant activities. The antioxidant activities of $\mathrm{ZnO}$ nanoparticles were exhibiting through scavenging of Nitric oxide, Hydrogen peroxide, and DPPH free radicals. Furthermore, the electrochemical
\end{abstract}


analysis of reduced Graphene Oxide-Zinc oxide (rGO-ZnO) nanocomposite shows that the prepared $\mathrm{rGO}-\mathrm{ZnO}$ nanocomposite has a high specific capacitance of about $667 \mathrm{~F} \mathrm{~g}^{-1}$ in comparison with the pure Zinc oxide nanoparticles $\left(200 \mathrm{~F} \mathrm{~g}^{-1}\right)$ and has good cycling stability of around 1000 cycles. The synthesis of multifunctional $\mathrm{ZnO}$ nanoparticles by using natural plant products like seeds, leaves, flowers, etc may help to explore as environment-friendly which is opposite to chemical synthesis.

\section{Keywords:}

Green synthesis, Zinc oxide nanoparticles (ZnO NPs), L. nepetifolia flower extract, photocatalytic activity, antioxidant activity, and electrochemical analysis.

\section{Introduction}

Nanotechnology is a multidisciplinary research area and covers all features of science and technology from the past few decades. $\mathrm{ZnO}$ nanoparticles have a wide application in the fields like optics, optoelectronics, bio medicinal, antimicrobial activities, and photocatalytic activity $[1,2]$. In recent years, the simplistic synthesis of $\mathrm{ZnO}$ nanoparticles is increasing because of its wider application. The synthesis of $\mathrm{ZnO}$ nanoparticles can be done by several methods such as sol-gel process, pulsed laser deposition, thermal evaporation, mechanical milling method, spray pyrolysis, organometallic microwaveassisted methods $[3,4]$. Moreover, these types of methods are highly expensive, the use of toxic chemicals are high, labour-intensive (need large workforce), and dangerous to the environment. Some toxic chemicals involved in the chemical methods have harmful effects in the medical field.

Metal oxide nanoparticles ( $\mathrm{ZnO}$ nanoparticles) are non-poisonous, multiple functions, highly biocompatible, very low cost, and ecofriendly substance when compared to metallic nanoparticles $[5,6]$. $\mathrm{ZnO}$ nanoparticles have wide application in various field like the food 
industry, sunscreen lotions, paints and coatings industries due to their strong UV protection, optoelectronic devices, removal of heavy metals from water, and in the medical fields like nano diagnostics, nanomedical, gene and drug delivery, and high antimicrobial activities $[7,8]$. Due to its pollution, toxicity, and danger to the environment, many researchers have proposed preparing the $\mathrm{ZnO}$ nanoparticles by green synthesis method from the high costeffective, or by using natural wastes of biological or plant-like seed, barks, leaf, flower, stem, etc $[9,10]$.

Agricultural wastes contain a high number of secondary metabolites which reduces metal ions $\left(\mathrm{zn}^{2+}\right)$ by biologically active substances like an enzyme, amino acid, phenolic compound, and vitamin. By using agro-waste materials lowers the cost of the synthesis and minimize the energy needed when compared to both methods (physical or chemical); and also, they lower the need for using highly dangerous chemicals or other byproducts, further highlights the essential of the green route synthesis method $[11,12]$.

Leonotis nepetifolia is a tropical Africa and Southern India flower belonging to the family Lamiaceae. Therefore L. nepetifolia flowers are cost-less agro-waste that contains secondary metabolites, during the biogenesis of metallic nanoparticles they could additionally act as reducing agents, capping agents, and stabilizing agents in a very simple and cost-effective synthesis method [13]. The green synthesis of $\mathrm{ZnO}$ nanoparticles can be affected by various process and parameters which include both the type and concentration of precursor solution, its $\mathrm{pH}$ value, reaction time, temperature, and the ratio between precursor and the biological source [14,15].

The photocatalytic activity of $\mathrm{ZnO}$ nanoparticles is affected by various aspects such as the size of the particles, shape or morphology, and surface defects [16]. The catalytic studies were described for the synthesis of $\mathrm{ZnO}$ nanoparticles using L. nepetifolia flower 
extract under visible light irradiation. Further, the synthesized ZnO NPs were characterized by Ultraviolet-visible (UV-Vis) spectroscopy, Fourier Transform Infrared (FT-IR) spectroscopy, X-ray diffraction (XRD) analysis, Dynamic Light Scattering (DLS) analysis, Raman spectroscopy, Scanning Electron Microscopy (SEM) and Energy Dispersive X-ray (EDX) spectroscopy, Transmission Electron Microscopy (TEM), and Thermogravimetric Analysis (TGA).

\section{Experimental Part}

\subsection{Materials}

The chemicals like $\mathrm{Zn}\left(\mathrm{NO}_{3}\right)_{2}$ (Zinc nitrate), distilled water, and other reagents used in this work were purchased from Sigma-Aldrich, India.

\subsection{Process and Preparation of the Extract}

The flower extract was prepared by the following process, the L. nepetifolia flower is washed many times with water and dried under sunlight. Approximately $10 \mathrm{~g}$ of L. nepetifolia dried flowers was taken in a washed $250 \mathrm{~mL}$ beaker and mixed with $100 \mathrm{~mL}$ of $\mathrm{ddH}_{2} \mathrm{O}$ (doubledistilled water). Then the mixtures were boiled at $100{ }^{\circ} \mathrm{C}$ for around $10 \mathrm{~min}$. Afterwards, the solution colour changes from colourless to reddish-brown. Afterwards, the flower extract is transferred to Whatman No. 1 filter paper and then that filtrate was kept in the refrigerator for further usage. Finally, it is used for the synthesis of Zinc oxide nanoparticles.

\subsection{Biosynthesis of $\mathrm{ZnO}$ nanoparticles}

The Zinc oxide nanoparticles were synthesized by mixing L. nepetifolia flower extract (50 $\mathrm{mL}$ ) and zinc nitrate $(5 \mathrm{~g})$ and then that mixture was stirred by using the magnetic stirrer at 60 $80{ }^{\circ} \mathrm{C}$ for $1 \mathrm{~h}$. We obtain a reddish paste when the temperature reaches $70{ }^{\circ} \mathrm{C}$, this paste is dried in the dryer at $100-130{ }^{\circ} \mathrm{C}$, for $40-45 \mathrm{~min}$. Zinc oxide nanoparticles were obtained in the form 
of pale yellow coloured powder. Then, it is collected and dehydrated at $70{ }^{\circ} \mathrm{C}$ utilizing a hot air oven overnight. Finally, it is stored in a vacuum desiccator.

\subsection{Purification of $\mathrm{ZnO}$ nanoparticles}

To recover the $\mathrm{ZnO}$ nanoparticles, the $\mathrm{L}$. nepetifolia flower extract $(10 \mathrm{~mL})$ was mixed with the zinc sulphate solution $(90 \mathrm{~mL})$. Afterwards, that mixture was placed at room temperature for nearly 4 days and then the nanoparticles formed was visually observed at regular intervals of time. After completing the incubation, the solution was allowed to centrifuge at $5000 \mathrm{rpm}$ for $15 \mathrm{~min}$. Then the precipitate was collected and suspended in distilled water $\left(\mathrm{dH}_{2} \mathrm{O}\right)$ for further centrifugation. The collected precipitate was washed two to three times to remove the impurities present in it. Finally, the nanoparticles obtained was dried in an air oven overnight till the moisture is fully discarded and the dried nanoparticles were collected for further use.

\subsection{Characterization}

The Ultraviolet-Visible absorption (UV-Vis) spectrum of the sample was collected by using the Jasco (V-560) spectrometer with a wavelength of $200-700 \mathrm{~nm}$. Fourier transform infrared (FT-IR) spectrum of the synthesized ZnO nanoparticles was obtained from the 460 Plus FTIR spectrometer (JASCO) instrument. The identification of the phase of the annealed powdered nanoparticle is recorded by using the JEOL JDX $8030 \mathrm{X}$-ray diffractometer instrument of $\mathrm{Cu}$

- $\mathrm{K} \propto$ with radiation of $1.5406 \mathrm{~A}^{0}$. The particle size was measured by a dynamic light scattering (DLS) analyzer [ZEN3600 He-Ne laser $(633 \mathrm{~nm})$, the size ranges from $0.3 \mathrm{~nm}$ to $10 \mu \mathrm{m}$ ]. Raman spectrum was carried out by using LabRAM HR evolution microscopic confocal Raman spectrometer (Horiba, Japan). The scanning electron microscopy (SEM) studies and Energy Dispersive X-ray (EDX) spectroscopy was recorded by using FE-SEM, SU8000, Hitachi, Tokyo, Japan. Transmission Electron Microscopy (TEM) analysis was performed on the FEI TECNAI T20 G2 instrument operated at an acceleration voltage of $120 \mathrm{kV}$. Thermal 
analysis and decomposition of the synthesized nanoparticles are observed by the differential scanning calorimetry / thermogravimetric analysis (DSC/TGA-50, SHIMADZU) measured from $25-700{ }^{0} \mathrm{C}$ at a heating rate of $10{ }^{\circ} \mathrm{C} / \mathrm{min}$.

\subsection{Photocatalytic degradation of MB by ZnO NPs}

Bioremediation studies were performed for methylene blue $\left(\mathrm{C}_{16} \mathrm{H}_{18} \mathrm{ClN}_{3} \mathrm{~S}\right)$ using sunlight as a source [17]. During the reaction, the flux in lighting was studied at the starting point of the analysis it was $1225 \mathrm{~W} / \mathrm{m}^{2}$ and then it reaches $1275 \mathrm{~W} / \mathrm{m}^{2}$ for $70 \mathrm{~min}$. The light intensity was determined to be the same all over the study. Weigh approximately $0.3 \mathrm{mg}$ of $\mathrm{ZnO}$ nanoparticles and dissolved in $15 \mathrm{~mL}$ of the solution (MB dye) and then sonicated that solution for $25 \mathrm{~min}$ in the darkroom. Likewise, the control was kept under the same condition, then it changes the colour of the dye solution when compared with the nanoparticles $[18,19]$. Degradation of the dye was confirmed by the change in colour. The colour of the solution (MB) was changed from blue to colourless. For methylene blue, the UV absorption peak was obtained at $660 \mathrm{~nm}$. The bioremediation process was observed by a drop in the peak intensity when exposed to solar light. UV absorption spectra were determined after changing light exposure time using a UV-Vis spectrophotometer to display the degradation rate for methylene blue at the highest wavelength of $\lambda_{\max }=660 \mathrm{~nm}$ [20]. According to the following formula, the degradation percentage of the dye can be calculated,

$$
\% \text { degradation }=\left(\mathrm{I}_{0}-\mathrm{I} / \mathrm{I}_{0}\right) * 100
$$

where, $\mathrm{I}_{0}$ is the starting intensity of the $\mathrm{MB}$,

I is the intensity after photodegradation.

\subsection{Haemolytic activity}


Haemolysis is defined as the destruction of red blood cells (RBC) which causes the release of haemoglobin into the blood plasma due to the damage of the erythrocyte membrane. Then, haemolysis takes place in a higher area it leads to a very dangerous pathological condition. The following process defines the haemolytic activity study was carried out against synthesized $\mathrm{ZnO}$ nanoparticles. $9 \mathrm{~mL}$ of the Heparinized human blood sample was collected; $1.5 \mathrm{~mL}$ of 3.9 $\%$ sodium citrate was dissolved slowly. Afterwards, this can highly inhibit blood coagulation. Then the rejection of supernatant having platelet-poor plasma occurred. Once the plasma is discarded, it was washed thrice with $10 \mathrm{~mL}$ of PBS (phosphate buffer saline) solution having a $\mathrm{pH}$ value of 7.4 to separate the RBCs buffy coat. The suspension of cells in PBS takes place to get the cells suspended uniformly. Different concentrations of $\mathrm{ZnO}$ nanoparticles of untreated RBCs, 25, 50, 75, 100, $125 \mu \mathrm{g} / \mathrm{mL}$ were taken in separate sample tubes. Add $2 \mathrm{~mL}$ of erythrocyte suspension to all the test tubes and the sample tubes were reversed. Then sample tubes were shaken slowly to keep the blood in contact with synthesized $\mathrm{ZnO}$ nanoparticles and simultaneously incubated at $36{ }^{\circ} \mathrm{C}$ for $85 \mathrm{~min}$ [21]. Centrifugation of the sample occurred at high $3000 \mathrm{rpm}$ of around $6 \mathrm{~min}$. Separation of the supernatant was taken place and $540 \mathrm{~nm}$ is the absorbance measured against a PBS blank solution. Triton X-100 (0.1\% v/v) and PBS were used as positive and negative control respectively. Haemolysis percentage (\%) was calculated by the formula shown below

$$
\text { Haemolysis percentage }=\frac{(\text { The absorbance of sample }- \text { Absorbance of Blank })}{\text { (Absorbance of positive control })} \times 100
$$

\subsection{Antioxidant Activity of Synthesized ZnO NPs by Flower Extract}

\subsubsection{Nitric oxide scavenging assay}

Nitric oxide scavenging assay of L. nepetifolia was determined by Griess ilosvay reaction using sodium nitroprusside and Griess reagent used as an important ingredient. $100 \mu \mathrm{L}$ of 10 $\mathrm{mM}$ sodium nitroprusside is dissolved in $100 \%$ of $\mathrm{CH}_{3} \mathrm{OH}$ (Methanol) was added slowly to 
various concentrations of flower extract (L. nepetifolia) and synthesized NPs (ZnO NPs) [(20$100 \mu \mathrm{g} / \mathrm{mL})]$. Ascorbic acid has been utilized as a standard. The prepared reaction mixture was placed at RT (Room Temperature) $\left[\left(20-25{ }^{0} \mathrm{C}\right)\right]$ for nearly $3 \mathrm{~h}$. After incubation, the reactant absorbance was determined at $546 \mathrm{~nm}$ and the scavenging rate is calculated by using the formula (a).

\subsection{2. $\mathrm{H}_{2} \mathrm{O}_{2}$ scavenging assay}

$\mathrm{H}_{2} \mathrm{O}_{2}$ scavenging assay of L. nepetifolia was estimated by monitoring the reduction of $\mathrm{H}_{2} \mathrm{O}_{2}$. Ascorbic acid was considered as a standard and various concentrations of L. nepetifolia flower extract or ZnO NPs (20-100 $\mu \mathrm{g} / \mathrm{mL})$ is dissolved in $\mathrm{dH}_{2} \mathrm{O}$ (Distilled water) and was mixed to an $\mathrm{H}_{2} \mathrm{O}_{2}$ solution, $600 \mu \mathrm{L}$ of $40 \mathrm{mM}$ in PBS. After the incubation process, the reactant absorbance was determined at $230 \mathrm{~nm}$ and the scavenging rate is calculated by using the formula (a).

\subsubsection{DPPH scavenging assay}

DPPH compound is a free radical which is used as a substrate to measure antioxidant activity. The reduction capacity of DPPH free radical was measured by the decrease in its concentration induced by the antioxidant activity. The free radical scavenging potential of the flower extract, antioxidant was observed by the degree of discolouration [22,23]. Antioxidant activity of flower extract (Leonotis nepetifolia) and synthesized ZnO NPs was estimated by DPPH free radical scavenging activity. $1 \mathrm{M} \mathrm{DPPH}$ solution of $500 \mu \mathrm{L}$ is mixed in $100 \%$ of methanol and then it was added equally to different concentrations of L. nepetifolia flower extract and ZnO NPs (20-100 $\mu \mathrm{g} / \mathrm{mL})$. Afterwards, shake the solution vigorously and then

place that solution for nearly 30 min of incubation in a dark place. After completion of incubation, the reactant absorbance was determined at $517 \mathrm{~nm}[24,25]$. Ascorbic acid was utilized as a positive control. 
The percentage of scavenging potential was measured by the formula given below

Scavenging activity $(\%)=\left[\left(\mathrm{A}_{\text {control }}-\mathrm{A}_{\text {sample }}\right) / \mathrm{A}_{\text {control }}\right] \times 100$

where $\mathrm{A}_{\text {control }}=$ Absorbance of a control,

$\mathrm{A}_{\text {sample }}=$ Absorbance of a sample.

\subsection{Preparation of $\mathrm{rGO} / \mathrm{ZnO}$ nanocomposite}

About $0.3 \mathrm{~g}$ of $\mathrm{ZnO}$ NPs and $\mathrm{rGO}$ of $1 \mathrm{~g}$ was mixed with $100 \mathrm{~mL}$ of distilled water $\left(\mathrm{dH}_{2} \mathrm{O}\right)$ and it is placed at ultrasonication for $30 \mathrm{~min}$ with constant stirring. Then the mixture obtained is filtered and dried in a dried oven. The nanocomposite $(\mathrm{rGO} / \mathrm{ZnO})$ obtained was stored in the vacuum desiccator under a nitrogen atmosphere.

\subsection{Electrochemical Measurements}

CHI electrochemical workstation (Model 660E, USA) with a typical three types of electrode was used to perform the electrochemical analysis in a $2 \mathrm{M} \mathrm{KOH}$ electrolyte solution. For electrochemical characterization, CV (Cyclic voltammetry), EIS (Electrochemical impedance spectroscopy) and CP (Chronopotentiometry) were used [26-28]. A platinum wire is used as a counter, a saturated calomel electrode as a reference and an active material coated with nickel foil as the working electrode. About 90 wt. $\%$ of this active material, 5 wt. $\%$ of acetylene black and 5 wt. \% of polytetrafluoroethylenes were ground and mixed with N-methyl-2pyrrolidone (NMP) to get a homogeneous slurry. Then using a doctor blade method, the slurry is coated uniformly on a nickel foil $\left(1 \mathrm{~cm}^{-2}\right)$ and dried for $12 \mathrm{hrs}$ at $90^{\circ} \mathrm{C}$. The mass of the active material contains $5 \mathrm{mg}$ and act as a working electrode. Around $0.01 \mathrm{~Hz}-100 \mathrm{k} \mathrm{Hz}$ of frequency range and with $10 \mathrm{mV}$ of the sinusoidal signal, the EIS was conducted. Then, $5 \mathrm{~A} \mathrm{~g}^{-}$ ${ }^{1}$ of current density, we tested the cycling stability [29-31]. From the data of CV and GCD, the Energy density $\left(d_{e}, \mathrm{Wh} \mathrm{kg}^{-1}\right)$, average Power density $\left(\mathrm{d}_{\mathrm{p}}, \mathrm{W} \mathrm{kg}^{-1}\right)$ and Specific capacitance $(\mathrm{F}$ $\mathrm{g}^{-1}$ ) were calculated using the following formulas (a-d): 


$$
\begin{array}{ll}
\mathrm{SC}(\mathrm{CV})=\frac{\int I \mathrm{~d} V}{v m \Delta V} & \cdots(\mathrm{a}) \\
\mathrm{SC}(\mathrm{GCD})=\frac{I \times \Delta t}{m \times \Delta V} & \cdots(\mathrm{b}) \\
d_{\mathrm{e}}=\frac{\operatorname{SCs} \times(\Delta V)^{2}}{2} & \cdots(\mathrm{c}) \\
d_{\mathrm{p}}=\frac{d_{\mathrm{e}}}{\Delta t} & \cdots(\mathrm{d})
\end{array}
$$

where $m$ is the mass of an active materials $(\mathrm{g})$,

I is the current load $\left(\mathrm{A} \mathrm{g}^{-1}\right)$,

$v$ is the scanning rate,

$\Delta V$ is the potential difference, and

$\Delta t$ is the discharge time.

\section{Results and Discussion}

\subsection{UV-Visible spectroscopy}

UV-Vis (Ultraviolet-Visible) spectroscopy is the technique commonly used to determine the optical properties of the nanoparticle, and it also explains the formation of $\mathrm{ZnO}$ nanoparticles in an aqueous solution. Fig. 1 shows the UV-Vis spectra of extract and synthesized ZnO NPs. The absorption spectrum of Leonotis nepetifolia flower extract showed a peak at the wavelength of $275 \mathrm{~nm}$ which corresponds to components like glycosides that can be used as a capping agent and flavonoids as a reducing agent for the synthesis of Zinc Oxide nanoparticles. The absorption spectrum of the ZnO NPs showed single broadband at the wavelength of $340 \mathrm{~nm}$. This peak is assigned as the transitions of electrons from the valence band (VB) to the conduction band (CB) $\left(\mathrm{Zn}_{3 \mathrm{~d}} \rightarrow \mathrm{O}_{2 \mathrm{p}}\right)$. Due to its blue shift, the reduction in the size of the $\mathrm{ZnO}$ nanoparticle causes a decrease in the wavelength and increases the frequency. 
Thus, $\mathrm{ZnO}$ nanoparticles absorb at a lesser wavelength than that of bulk $\mathrm{ZnO}$. The free electrons in $\mathrm{ZnO}$ nanoparticles give rise to the Surface plasmon Resonance (SPR) absorption band, which occurred due to the combined vibration of electrons present in the nanoparticles with the light waves. These SPR thin peaks show that the particles are in a nanosized range with narrow particle size distribution.

The SPR (Surface Plasmon Resonance) and energy bandgap $\left(E_{g}\right)$ of the green synthesized $\mathrm{ZnO}$ nanoparticles were calculated with the wavelength range of 200-700 $\mathrm{nm}$ using the UVVisible spectroscopic method. $\mathrm{ZnO}$ nanoparticles were dispersed in distilled water $\left(200 \mathrm{mg} \mathrm{L}^{-}\right.$

${ }^{1}$ ) and exposed to an ultrasonic bath for $15 \mathrm{~min}$ [32,33]. The bandgap energy of $\mathrm{ZnO}$ nanoparticles is calculated by using the formula

$$
\mathrm{E}=\mathrm{hc} / \lambda
$$

where h - Planck constant $\left(6.626 \times 10^{-34} \mathrm{~J} \mathrm{~s}\right)$,

c - velocity of light $\left(2.99 \times 10^{8} \mathrm{~m} \mathrm{~s}^{-1}\right)$, and

$\lambda_{\max }$ - maximum absorption wavelength.

The bandgap energy calculated using the above formula for $\mathrm{ZnO}$ NPs was determined to be $3.24 \mathrm{eV}$ (Fig. 1) is smaller when compared to bulk $\mathrm{ZnO}(3.37 \mathrm{eV})$.

\subsection{FT-IR spectroscopy}

FT-IR studies is an analytical technique widely used to detect various functional groups, ionic interaction, and metal-oxygen bonds that exist in Leonotis nepetifolia flower extract and the synthesized $\mathrm{ZnO}$ nanoparticles. Fig. 2 shows the spectra for extract and synthesized $\mathrm{ZnO}$ NPs. Strong stretching at $3730 \mathrm{~cm}^{-1}$ corresponds to the sharp OH stretching frequency of alcohol. The broad stretching peak at $3442 \mathrm{~cm}^{-1}$ and $3411 \mathrm{~cm}^{-1}$ is due to the $\mathrm{OH}$ group for the extract and $\mathrm{ZnO}$ NPs. The peak at $2920 \mathrm{~cm}^{-1}$ and $2914 \mathrm{~cm}^{-1}$ is due to the $-\mathrm{CH}$ stretching 
frequency of the hydroxyl compound. The strong absorption peak at $2384 \mathrm{~cm}^{-1}$ corresponds to the stretching vibration of $\mathrm{O}=\mathrm{C}=\mathrm{O}$. The peak at $1614 \mathrm{~cm}^{-1}$ and $1590 \mathrm{~cm}^{-1}$ is mainly due to stretching vibration of $\mathrm{C}=\mathrm{C}$ of the alkene group. Few absorption peaks at $1352 \mathrm{~cm}^{-1}, 865 \mathrm{~cm}^{-1}$, $1432 \mathrm{~cm}^{-1}$ have been attributed to - $\mathrm{CH}$ stretching frequency. The absorption peak at $1003 \mathrm{~cm}^{-}$

${ }^{1}$ corresponds to the $\mathrm{C}-\mathrm{N}$ bond stretching frequency of the primary amine of the $\mathrm{ZnO}$ NPs. The peak at $720 \mathrm{~cm}^{-1}$ and $701 \mathrm{~cm}^{-1}$ is might be due to $\mathrm{C}-\mathrm{H}$ out of plane bending. Stretching peak $1048 \mathrm{~cm}^{-1}$ appears due to the stretching frequency of $\mathrm{C}-\mathrm{O}$ vibration. The peaks at $550 \mathrm{~cm}^{-1}$ and $500 \mathrm{~cm}^{-1}$ correspond to the stretching vibration of Metal-Oxygen ( $\left.\mathrm{Zn}-\mathrm{O}\right)$ [34-36].

\subsection{XRD Analysis}

X-Ray Diffraction studies are used to measure the crystalline nature of synthesized $\mathrm{ZnO}$ powder. The XRD pattern of the synthesized nanoparticles was shown in Fig. 3. XRD studies were used to determine the crystal phase of the nanoparticles. The intense peaks were observed $2 \theta$ from $20-80$. XRD pattern shows an intense peak obtained $2 \theta$ values at $31.68^{0}, 34.51^{0}$, $36.27^{0}, 47.68^{0}, 56.55^{0}, 63.05^{0}, 66.68^{0}, 68.11^{0}, 69.21^{0}, 73.02^{0}, 77.16^{0}$ are due to corresponding diffractions from the lattice planes (h, 1, k) are (100), (002), (101), (102), (110), (103), (200), (112), (201), (004), (202) respectively [37-39]. The particle size of synthesized ZnO NPs can be measured by Debye - Scherrer's formula i.e

$$
\mathrm{D}=\frac{K \dot{\lambda}}{\beta \cos \theta} A
$$

where D - Particle size of the nanoparticles

K - Scherrer's constant

$\lambda$ - Wavelength of the X-ray

$\beta$ - Additional peak width at half the peak height.

$\theta$ - Bragg angle 
This equation is used to determine the crystalline size of about $25.68 \mathrm{~nm}$. The sharp and narrow diffraction peak observed at (101) was $25.68 \mathrm{~nm}$. The crystallinity of synthesized $\mathrm{ZnO}$ nanoparticle was confirmed by the narrow peak. The XRD pattern does not show any other impurity peak indicates the pure $\mathrm{ZnO}$ nanoparticles are prepared.

\subsection{Dynamic light scattering analysis}

DLS analysis is a non-invasive technique widely used to measure the particle-size distribution (PSD) of macromolecules and small particles in dilute suspension using a narrow laser beam and scattering of light are noticed by a fast single-photon detector at a well-known scattering angle $\theta$. The initial measurement of DLS has performed with the intensity- weighted particle with clearly defined PSD. The particle size starting from 20 to $25 \mathrm{~nm}$ with an average particle size of $\mathrm{ZnO}$ nanoparticles in an aqueous medium is $22.14 \mathrm{~nm}$. The DLS results showed a single peak and narrow distribution at room temperature. In DLS analysis comparatively radial symmetry of size distribution images shows the uniformity of the synthesized ZnO NPs [40,41]. The particle size measured using the DLS method was also supported by XRD analysis $(25.68 \mathrm{~nm})$.

\subsection{Raman Analysis}

Raman spectra of the synthesized nanoparticles were shown in Fig. 5. The Raman spectrum is important to determine the crystallization process, vibrational property, structural disorder, and defects in nanostructures. The Raman spectra are used to obtain the vibrational properties of synthesized $\mathrm{ZnO}$ nanoparticles. As stated in the group theory, the given formula used to measure

the optical modes

$$
\Gamma \text { opt }=\mathrm{A} 1+2 \mathrm{~B} 2+\mathrm{E} 1+2 \mathrm{E} 2
$$

where A1, E1 are the modes of two active polar branches, it is split into Longitudinal Optical (LO) and Transversal Optical (TO) components with various frequencies. A1, E1, and 
E2 are the modes of the first-order phonon. Both the phonon modes (A1 and E1) obtained are polar and both seem to be Raman and infrared (IR) active whereas the mode (E2) is non polar and Raman active only $[42,43]$. The first-order Raman modes were obtained at $90 \mathrm{~cm}^{-1}$, $380 \mathrm{~cm}^{-1}, 420 \mathrm{~cm}^{-1}, 540 \mathrm{~cm}^{-1}, 582 \mathrm{~cm}^{-1}$, and $680 \mathrm{~cm}^{-1}$ which represents to the $\mathrm{E}_{2}$ (low), $\mathrm{A}_{1}$ (high), $E_{2}$ (high), $A_{1}(L O)$ and $E_{1}(L O)$ respectively. The second-order phonon has presented at about $200 \mathrm{~cm}^{-1}$ that is assigned to $2 \mathrm{E}_{1}(\mathrm{low})$. Finally, the multiphonon mode was obtained at $330 \mathrm{~cm}^{-}$

${ }^{1}$ which corresponds to $\mathrm{E}_{2}$ (high) - $\mathrm{E}_{2}$ (low).

\subsection{SEM and EDX analysis}

The SEM image of the synthesized nanoparticles was shown in Fig. 6. The shape and size of synthesized $\mathrm{ZnO}$ nanoparticles can be determined by this analysis. The different magnifications range from $2 \mu \mathrm{m}-200 \mu \mathrm{m}$ are seen through SEM images. Most of the $\mathrm{ZnO}$ nanoparticles are spherical with high agglomeration are observed and the average particle size from 25 to $35 \mathrm{~nm}$ is confirmed by SEM images. The single nanoparticles cannot be considered by the intense observation of the SEM images. Then synthesized $\mathrm{ZnO}$ nanoparticles are analysed by EDX (Energy-Dispersive X-ray) spectroscopy. The elemental composition of the $\mathrm{ZnO}$ nanoparticles is determined by the EDX analysis. EDX analysis verified the existence of synthesized ZnO NPs. Using EDX the presence of components such as zinc (76.26\%), oxygen $(20.51 \%)$, and carbon $(3.23 \%)$ is determined. EDX results indicate that there is a variation from stoichiometry, when we consider the atomic weight of the elements, then we obtain the number of oxygen than zinc. But the synthesized $\mathrm{ZnO}$ was not stoichiometric, it can be known by these percentages and then presented defects, mostly interstitial oxygen (Oi) gives the excess of this element in the sample. A strong signal is revealed for zinc by EDX spectra. Carbon is present in very low amounts which indicates the action of plant phytochemical groups in the reduction process and capping method of the synthesized $\mathrm{ZnO}$ nanoparticles. No 
other elements were determined, this shows the pure $\mathrm{ZnO}$ nanoparticles obtained by green synthesis $[44,45]$.

\subsection{TEM analysis}

Fig. 7 indicates the TEM image of the synthesized nanoparticles. Variations of the particle shape or the presence of larger or smaller particles are directly visualized by the TEM images. The size and morphology of the synthesized $\mathrm{ZnO}$ nanoparticles were studied using TEM. TEM images show irregularly shaped nanoparticles with a distribution of agglomerates. TEM images revealed that the $\mathrm{ZnO}$ nanoparticle was mostly spherical with size ranges from 25 to $100 \mathrm{~nm}$. Due to green synthesis, some shapes were oval, where the biological molecules can act as capping on $\mathrm{ZnO}$ nanoparticles. Then $\mathrm{X}$-rays intensities which are dispersed by a sample as a function of scattering angle are measured by a technique known as SAXS (Small-angle X-ray Scattering). For the homogeneous sample, reliable results based on the evaluation of the excess number of particles are obtained by an ideal method SAXS. More accurately, the highly annealed sample at $500{ }^{0} \mathrm{C}$ reveals a polycrystalline structure mainly as per the observed diffraction rings (100), (002), (101), (102), (103), (110), (112). It is observed that the most intense diffraction ring at (100) [46,47].

\subsection{Thermogravimetric and differential scanning calorimetry analysis}

The TGA of the synthesized nanoparticles was shown in Fig. 8. The thermal analysis technique is used to determine the physical changes of the substance at a controlled temperature. Thermogravimetric analysis (TGA) is a technique used to characterize the material by measuring its change in mass as a function of temperature. The transfer of heat in the sample is determined by DSC (Differential Scanning Calorimetry) analysis. TGA / DSC analysis of synthesized nanoparticles which provides concurrent weight change, heat flow respectively on the same sample. From the TGA diagram of $\mathrm{ZnO} \mathrm{NP}$, three stages of weight 
loss can be detected. The first weight loss of about 5-10 \% that had been reported from 25-120 ${ }^{0} \mathrm{C}$ is because of the evaporation of water molecules in the sample. The simultaneous second weight loss of around $20-30 \%$ was observed in the range of $120-210{ }^{0} \mathrm{C}$ is attributed to decarboxylation. The third weight loss of about $210-350{ }^{\circ} \mathrm{C}$ indicates the formation of $\mathrm{ZnO} \mathrm{NP}$. No weight loss is recorded between $350-700{ }^{\circ} \mathrm{C}$ was seen in the TGA curve, which indicates the $\mathrm{ZnO}$ nanoparticles formed as a final product. Three quasi sharp endothermic peaks were recorded from the DSC analysis. The first endothermic peak was observed at $140{ }^{0} \mathrm{C}$ was attributed to the evaporation of the water absorbed from the sample and the second endothermic peak at $220{ }^{\circ} \mathrm{C}$ is due to the decomposition of organic molecules present in the sample. The third endothermic peak at $390{ }^{\circ} \mathrm{C}$ is due to the decomposition of precursor to $\mathrm{ZnO} \mathrm{NP}[48,49]$.

\subsection{Photocatalytic activity of $M B$}

The absorption spectrum of the MB polluted sample at various intervals of photocatalytic activity is shown in Fig. 9a. The photocatalytic activity was carried out for methylene blue (MB) using the flowers of Leonotis nepetifolia, $\mathrm{ZnO}$ nanoparticles were synthesized. The natural light source was taken from the sun and the absorption spectra at $660 \mathrm{~nm}$ are obtained for methylene blue. The initial step involves $\mathrm{MB}$ dye molecules are adsorbed on $\mathrm{ZnO}$ nanoparticles which results in the dye sensitization of ZnO. Through UV light, the VB (Valence Band) contains electrons ( $\mathrm{e}^{-}$) of highly dye-sensitized $\mathrm{ZnO}$ get excited to the $\mathrm{CB}$ (Conduction Band) with equal amounts of $\mathrm{h}^{+}$(holes) was produced in the Valence Band. The more positive potential is found in the Conduction Band of $\mathrm{ZnO}$, the superoxides are produced by the reactions of oxygen molecules, and the surface electrons. The separated $\mathrm{h}^{+}$(holes) will interact with the $\mathrm{H}_{2} \mathrm{O}$ (electron donors) forms active $\mathrm{OH}$, few free radicals. Following, the attack of surface-adsorbed MB dye molecules with the produced $\mathrm{h}^{+}$and other free radicals $\left(\cdot \mathrm{OH}, \mathrm{O}_{2} 2^{-}\right.$), which gives the decolouration and open ring reaction. Then in the reaction of photocatalytic activity of MB dye solution contains active species such as $\mathrm{OH}$ (hydroxyl radicals), $\mathrm{h}^{+}$(holes), 
and $\mathrm{O}_{2} \cdot-$ (superoxide oxide radical anion). Hydroxyl radicals, and Holes has an essential role in the degradation of MB dyes by Zinc oxide nanoparticles using UV light.

$$
\begin{array}{ll}
\text { i. } & \mathrm{MB} \text { (aqueous solution) }+\mathrm{ZnO} \rightarrow \mathrm{MB}-\mathrm{ZnO} \\
\text { ii. } & \mathrm{MB}-\mathrm{ZnO}+\mathrm{h} v \rightarrow \mathrm{MB}-\mathrm{ZnO}\left(\mathrm{h}^{+}+\mathrm{e}^{-}\right) \\
\text {iii. } & \mathrm{e}^{-}+\mathrm{O}_{2} \rightarrow \mathrm{O}_{2}^{--} \\
\text {iv. } & \mathrm{h}^{+}+\mathrm{H}_{2} \mathrm{O} \rightarrow \mathrm{OH}+\mathrm{H}^{+} \\
\text {v. } & \mathrm{MB}-\mathrm{ZnO}+\mathrm{h}^{+} / \mathrm{OH} / \mathrm{O}_{2}^{--} \rightarrow \mathrm{ZnO}+\mathrm{H}_{2} \mathrm{O}+\mathrm{CO}_{2}+\text { by-products. }
\end{array}
$$

The adsorption kinetics of photodegradation was exhibited pseudo-first-order kinetics. The rate equation is given as

$$
-\ln \left(\mathrm{C} / \mathrm{C}_{0}\right)=\mathrm{Kt}
$$

where $\mathrm{C}_{0}$ is the first concentration of the $\mathrm{MB}$ dye solution,

$\mathrm{C}$ is the concentration after photodegradation,

$\mathrm{K}$ is the rate constant, and

$\mathrm{T}$ is the time taken.

Degradation has occurred efficiently when the rate constant is less than 1. For reactant, the degradation rate is measured and found to be $0.3156 \mathrm{mg} / \mathrm{L} \mathrm{min}$. The high photocatalytic activity is due to the electrostatic interaction between the anionic methylene blue dye and the positive zeta potential of $\mathrm{ZnO}$ nanoparticles. Additionally, the physical interaction between the functional groups on the $\mathrm{MB}$ dye and the oxygen group of $\mathrm{ZnO}$ is the reason for the adsorption of MB dye effectively. Fig. 9b presents the time profile of MB photocatalytic degradation efficiency. Around $45 \%$ of the total Methylene blue concentration was degraded within 20 min of the photocatalysis with a final Methylene blue degradation efficiency of $94 \%$ at the finish of $70 \mathrm{~min}$. 


\subsection{Haemolytic activity of ZnO NPs}

Many bio-active molecules may concentrate on toxic problems is known as haemolysis, and it is characterized by the breakdown of human RBC (erythrocytes) which forms the haemoglobin. Damage to essential organs such as the heart, kidney, and liver was caused by the free haemoglobin in plasma. Then it is important to examine the haemolytic studies of the bio-active molecules. The haemolytic activity is considered as the simple, inexpensive, and fast method for initial toxicity evaluation. Fig. 10a shows the results of the haemolytic assay of positive control, negative control, and ZnO NPs. The percentage of lysis is $98.5 \%$ and $0.9 \%$ for positive and negative control respectively, while $125 \mu \mathrm{g} / \mathrm{mL}$ of $\mathrm{ZnO}$ NPs exhibited $3.5 \%$ of total haemolytic activity and there was no destruction of red blood cells. Haemolytic activity of synthesized $\mathrm{ZnO}$ nanoparticles was less considerable, implying its safe nature in the chemotherapeutic application. Haemolytic activity was studied for various concentrations (25, $50,75,100,125 \mu \mathrm{g} / \mathrm{mL}$ ) and compared with untreated RBCs (Fig. 10b). Both the number of dead cells and the concentration of $\mathrm{ZnO}$ NPs were increased and we observe the maximum haemolysis (3.5\%) for $125 \mu \mathrm{g} / \mathrm{mL}$. Thus, a low concentration of nanoparticles can be used in pharmacological investigations due to their biocompatibility and non-toxic behaviour.

\subsection{Antioxidant Activity of ZnO NPs}

\subsubsection{Nitric oxide scavenging assay}

From this study, the results obtained show that the scavenging activity of NO (nitric oxide) increases with an equal increase of various concentrations $(20-100 \mu \mathrm{g} / \mathrm{mL})$ for the Ascorbic acid, extract, and $\mathrm{ZnO}$ nanoparticles. The scavenging assay of the extract (85\%) and $\mathrm{ZnO}$ NPs (70\%) are lower when compared to ascorbic acid (90\%) at $100 \mu \mathrm{g} / \mathrm{mL}$. 


\subsection{2. $\mathrm{H}_{2} \mathrm{O}_{2}$ scavenging assay}

From this study, the results obtained show that the scavenging activity of $\mathrm{H}_{2} \mathrm{O}_{2}$ (hydrogen peroxide) increases with an equal increase of various concentrations $(20-100 \mu \mathrm{g} / \mathrm{mL})$ for the Ascorbic acid, extract, and ZnO NPs. The activity of the ascorbic acid (90\%) and ZnO NPs $(70 \%)$ are lower when compared to extract $(85 \%)$ at $100 \mu \mathrm{g} / \mathrm{mL}$.

\subsubsection{DPPH free radical scavenging assay}

Antioxidant activity is dependent on the reducing influence of (2, 2-diphenyl-1picrylhydrazyl) DPPH. The green synthesized nanoparticles having excellent antioxidant activity, due to small particle size with the larger surface area. ZnO NPs showed lower activity $(65 \%)$ as compared to extract $(90 \%)$ at $100 \mu \mathrm{g} / \mathrm{mL}$. The scavenging assay of $\mathrm{ZnO}$ NPs is low comparing to the activity obtained with Ascorbic acid (Positive control). The activity increase with increasing concentration. Green synthesized $\mathrm{ZnO}$ NPs show good scavenging activity.

\subsection{Electrochemical techniques}

\subsubsection{Cyclic voltammetry Analysis}

Fig. 14a shows the $\mathrm{CV}$ curves for the $\mathrm{rGO}$ and $\mathrm{rGO}-\mathrm{ZnO}$ nanocomposite using three types of electrodes in strong $2 \mathrm{M} \mathrm{KOH}$ electrolyte solution in the potential range (-1 V to $1 \mathrm{~V}$ ) at a scan rate $(50 \mathrm{mV} / \mathrm{s})$ shows quasi-rectangular shape. Fig. 14b indicates the Cyclic Voltammetry curves of the entire composite at various scan rate. A quasi-rectangular shape of the CV curve without clear redox peaks indicates the perfect capacitance performance. According to equation (a) the specific capacitances of rGO-ZnO nanocomposite are found to be 667,560 , 432, 372, 295, and $251 \mathrm{~F} \mathrm{~g}^{-1}$ at 5, 10, 20, 50, and $100 \mathrm{mVs}^{-1}$ respectively. Furthermore, the specific capacitance of $\mathrm{rGO}$ is $153,118,97,82,74$, and $59 \mathrm{~F} \mathrm{~g}^{-1}$ respectively (Fig. 14c). The values of specific capacitance observed for synthesized $\mathrm{rGO}-\mathrm{ZnO}$ nanocomposite electrodes are larger when compared with the same reports obtained earlier (Table 1). The prepared rGO- 
$\mathrm{ZnO}$ nanocomposite has a very high specific capacitance is assigned to the more charge storage and higher accessibility of electrolyte towards the nanomaterials. Besides, rGO exhibits EDLC behaviour with higher surface area and conductivity whereas due to the synergistic effect the rGO-ZnO nanocomposite possesses better charge storage indicating the capacitance nature of rGO-ZnO nanocomposite. The $\mathrm{K}^{+}$ions in the $\mathrm{KOH}$ electrolyte interact with $\mathrm{rGO}-\mathrm{ZnO}$ to form rGO-ZnOK. The specific capacitance of nanocomposite decreases with an increase in the scan rate. This may be due to the movement of ions within the electrolyte solution increases slowly and then that lowers with the ease and extent of the charge storing process of the active material.

\subsubsection{Chronopotentiometry Analysis}

Knowing about the GCD (Galvanostatic Charge-Discharge) analysis and then the electrochemical performance, the materials were analysed by chronopotentiometry using strong $2 \mathrm{M} \mathrm{KOH}$ as electrolyte with a two-electrode cell (2E). Fig. 15a shows the straight and symmetrically triangular GCD curves of rGO-ZnO and $\mathrm{rGO}$ with excellent reversibility for outstanding carrier transport and ideal EDLC behaviour for good electrochemical performance indicating fast current-voltage response for the superior reversible redox process. Fig. 15b shows the curves (GCD) of rGO-ZnO nanocomposite at various current densities from 1 to 25 $\mathrm{A} \mathrm{g}^{-1}$. It shows an IR peak at $1 \mathrm{~A} \mathrm{~g}^{-1}(0.935 \mathrm{~V})$ to little change $(0.902 \mathrm{~V})$ showing that for electrolyte and $\mathrm{rGO}-\mathrm{ZnO}$ nanocomposite electrode the internal ion transfer arises easily. The specific capacitance is calculated based on equation (b) for discharge curves for rGO-ZnO (Fig. $15 \mathrm{c})$ are about $667,552,428,363,282$, and $232 \mathrm{~F} \mathrm{~g}^{-1}$ when the current density is $1.0,5.0,10$, 15,20 , and $25 \mathrm{~A} \mathrm{~g} \mathrm{~g}^{-1}$, which is several-fold higher than that of $\operatorname{rGO}(147,106,87,72,64$, and $\left.49 \mathrm{~F} \mathrm{~g}^{-1}\right)$. The superior performance of this nanocomposite is due to the morphology of the nanocomposite which helps the electrolyte ion transfer between electrode-electrolyte interface, the surface area of the nanocomposite which shortens the diffusion between the outer electrolytes to the inner surface and the defects are absent in rGO improves the electrical 
conductivity of rGO-ZnO nanocomposite which is suitable for higher electrical conductivity. The energy and power densities of rGO-ZnO nanocomposite material can be calculated from equation c and d using Ragone plots (Fig. 15d). The rGO-ZnO nanocomposite electrode shows the energy densities of $43.2,37.2,35.2,32.6,27.3$, and $23.5 \mathrm{Wh} \mathrm{kg}^{-1}$ concerning the power densities of 500, 1000, 1500, 2500, 5000, and $10000 \mathrm{~W} \mathrm{~kg}{ }^{-1}$. Similarly, rGO exhibit a maximum Energy density $\left(\mathrm{d}_{\mathrm{e}}\right)$ of $20.3 \mathrm{Wh} \mathrm{kg}^{-1}$ is smaller than $\mathrm{rGO}-\mathrm{ZnO}$ material.

\subsubsection{Electrochemical impedance spectroscopy}

The capacitive resistance behaviour of the material based on frequency, the high charge transfer kinetics involved within the three types of the electrode and the electrolyte diffusion property, then AC impedance measurements were achieved. Nyquist plots (Fig. 16) of nanocomposite $(\mathrm{rGO}-\mathrm{ZnO})$ and the electrode $(\mathrm{rGO})$ consist of a single straight line at the very low-frequency area is due to ideal electrical double-layer capacitive behaviour of the nanocomposite electrode and the semi-circle at the high-frequency area is obtained because of charge transfer resistance (Rct). Similarly, in a short $45^{\circ}$ regime, the intermediate frequency is known as the Warburg impedance region is due to the frequency-dependent ion transport or ion diffusion of the electrolyte in the electrode. To illustrate the magnitude of equivalent series resistance, the diameter of the semi-circle is acquired from the high-frequency range (inset) from the $\mathrm{x}$-intercept. It is observed that a decrease in internal resistance and increase in conductivity for smaller equivalent series resistance value of rGO-ZnO (4.3 $\Omega$ ) than rGO (5.2 $\Omega$ ). The inset of (Fig. 16) describes the equivalent circuit of the series electronic element includes $\mathrm{R}_{1}$ (electrolyte resistance) between the reference and working electrode and $\mathrm{R}_{2}(\mathrm{Rct})$.

To evaluate the practical applications of electrochemical supercapacitor electrodes, then we tested the long-term cycling stability. To analysis the electrochemical stability of nanocomposite electrode (rGO-ZnO) and $\mathrm{rGO}$ electrode, galvanostatic charge-discharge cycling tests were tested the current density at $10 \mathrm{~A} \mathrm{~g}^{-1}$ for 5000 cycles. Fig. 17 presents the 
specific conductance as a function of cycle number. $\mathrm{rGO}-\mathrm{ZnO}$ nanocomposite electrode exhibit outstanding cycling stability with the capacitance retention of $97.2 \%$ after 5000 cycles suggesting that the prepared $\mathrm{rGO}-\mathrm{ZnO}$ nanocomposite has a good potential for supercapacitor applications. This is mainly due to the good mechanical stability, flexibility, and perfect hybridization of nanocomposite electrode ( $\mathrm{ZnO}$ and $\mathrm{rGO}$ ).

\section{Conclusion}

The synthesis of ZnO NPs from the flowers of L. nepetifolia was successfully done in the present work. In this study, the biosynthesized ZnO NPs are environment friendly, non-toxic, and reduce the usage of chemicals when comparing with both physical method and chemical method. UV-Vis absorption spectrum shows the blue shift when compared to bulk $\mathrm{ZnO}$ which is assigned to the size effect. FTIR of ZnO NPs appears the band at $500 \mathrm{~nm}$ is due to vibration of Zn-O bonding. The XRD pattern confirms that the synthesized ZnO NPs exhibit spherical while zinc and oxide ions are present in the nanoparticles was observed by EDX analysis. The nanoparticles are fully agglomerated and then the average size of ZnO NPs is about $25.68 \mathrm{~nm}$ were confirmed by SEM and TEM images respectively. ZnO NPs show good photocatalytic activity for the photodegradation of methylene blue when compared with other Metal oxide nanoparticles and further, it reveals excellent antioxidant assay. The combined effect of $\mathrm{ZnO}$ and rGO shows the good electrochemical performance of the prepared $(\mathrm{rGO} / \mathrm{ZnO})$ nanocomposite electrode material when compared to pure $\mathrm{ZnO}$. Nanocomposite electrode material reveals the high specific capacitance $\left(667 \mathrm{~F} \mathrm{~g}^{-1}\right)$ and high cyclic stability. Therefore, the prepared $(\mathrm{rGO} / \mathrm{ZnO})$ nanocomposite was widely used as an electrode material for applications in energy storage. 


\section{Authorship contribution statements}

Gajendran Pavithra: Investigations, Writing-original draft, Formal analysis, Santhakumar: Supervision, Conceptualization The authors have fully read and approved the final version of the manuscript.

\section{Declarations of Competing Interests}

The authors declared that they have no competing interests.

\section{Acknowledgement}

We have to thank VIT University, Tamil Nadu, India for their technical and financial support without which the current investigation would be incomplete. We also thank Prof. N. Kumaraguru, and N. Samiveerappa, Bharathidasan University for supporting biological and electrochemical studies.

\section{References}

[1] S. Vijayakumar, B. Vaseeharan, B. Malaikozhundan, M. Shobiya, Laurus nobilis leaf extract mediated green synthesis of $\mathrm{ZnO}$ nanoparticles: Characterization and biomedical applications, Biomed \& Pharmacother 84 (2016) 1213-1222.

[2] J. Yan, J. Wang, L. Zhu, J. Wu. Green synthesis and characterization of zinc oxide nanoparticles using carboxylic curdlan and their interaction with bovine serum albumin, RSC Adv 6 (2016) 77752-77759.

[3] A. N. Deva Krupa, R. Vimala. Evaluation of tetraethoxysilane (TEOS) sol-gel coatings, modified with green synthesized Zinc oxide nanoparticles for combating microfouling, Mater. Sci. Eng. C 61 (2016) 728-735. 
[4] F. T. Thema, E. Manikandan, M. S. Dhlamini, M. Maaza. Green synthesis of ZnO nanoparticles via Agathosma betulina natural extract, Mater Lett 161 (2015) 124-127.

[5] S. O. Ogunyemi, Y. Abdallah, M. Zhang, H. Fouad, X. Hong, E. Ibrahim, Md. Mahidul Islam Masum, A. Hossain, Jianchu Mo \& Bin Li. Green synthesis of Zinc oxide nanoparticles using different plant extracts and their antibacterial activity against Xanthomonas oryzae pv. Oryzae, Artif cells, nanomed and biotechnol 47 (2019) 341-352.

[6] H. Agarwal, S. Venkat Kumar, S. Rajeshkumar. A review on green synthesis of zinc oxide nanoparticles - An eco-friendly approach, Resour-Effi Technol 3 (2017) 406-413.

[7] J. Santhoshkumar, S. Venkat Kumar, S. Rajeshkumar. Synthesis of zinc oxide nanoparticles using plant leaf extract against urinary tract infection pathogen, Resour-Effi Technol 000 (2017) 1-7.

[8] M. M. Alvesa, S. M. Andradea, L. Grenhob, M. H. Fernandesb, C. Santosa, M. F. Montemor. Influence of apple phytochemicals in $\mathrm{ZnO}$ nanoparticles formation, photoluminescence and biocompatibility for biomedical applications, Mater Sci \& Eng C 101 (2019) 76-87.

[9] F. M. Arvanaga, A. Bayramia, A. Habibi-Yangjehb, S. R. Pouran. A comprehensive study on antidiabetic and antibacterial activities of $\mathrm{ZnO}$ nanoparticles biosynthesized using Silybum marianum L seed extract, Mater Sci \& Eng C 97 (2019) 397-405.

[10] Y. A. Selim, M. A. Azb, I. Ragab, H. M. Abd El-Azim. Green Synthesis of Zinc Oxide Nanoparticles Using Aqueous Extract of Deverra tortuosa and their Cytotoxic Activities. Sci Repor 10 (2020) 1-9. 
[11] S. Awan, K. Shahzadi, S. Javad, A. Tariq, A. Ahmad, S. Ilyas. A preliminary study of influence of zinc oxide nanoparticles on growth parameters of Brassica oleracea var italic, J. Saudi Soc. Agric. Sci 20 (2021) 18-24.

[12] S. Yedurkar, C. Maurya, P. Mahanwar. Biosynthesis of Zinc Oxide Nanoparticles Using Ixora Coccinea Leaf Extract-A Green Approach, Int. J. Circuit Theory Appl 05 (2016) 1-14.

[13] A. Waseem, K. Divya. Synthesis, characterization and antimicrobial activities of ZnO nanoparticles using Euphorbia hirta leaf extract, J. King Saud Univ. Sci 32 (2020) 2358-2364.

[14] H. N. Shivananjaiah, K. Sailaja Kumari, M. S. Geetha. Green mediated synthesis of lanthanum doped zinc oxide: Study of its structural, optical and latent fingerprint application, J. Rare Earths 38 (2020) 1281-1287.

[15] Y. Zheng, L. Fu, F. Han, A. Wang, W. Cai, J. Yu, J. Yang. Green biosynthesis and characterization of zinc oxide nanoparticles using Corymbia citriodora leaf extract and their photocatalytic activity, Green Chem Lett and Rev 8 (2015) 59-63.

[16] S. Vijayakumara, S. Mahadevana, P. Arulmozhia, S. Sriramb, P. K. Praseetha. Green synthesis of zinc oxide nanoparticles using Atalantia monophylla leaf extracts: Characterization and antimicrobial analysis, Mater Sci Semicond process 82 (2018) 39-45.

[17] D. Suresh, P. C. Nethravathi, Udayabhanu, H. Rajanaika, H. Nagabhushana, S.C. Sharma. Green synthesis of multifunctional zinc oxide $(\mathrm{ZnO})$ nanoparticles using Cassia fistula plant extract and their photodegradative, antioxidant and antibacterial activities, Mater Sci Semicond Process 31 (2015) 446-454.

[18] L. Chen, L. Batjikh, J. Hurh, Y. Han, Y. Huo, H. Ali, J. Feng, E. Jahan, J. Chan, R. Mathiyalagan. Green synthesis of zinc oxide nanoparticles from root extract of Scutellaria 
baicalensis and its photocatalytic degradation activity using methylene blue, Optik 184 (2019) 324-329.

[19] J. T. Adeleke, V. Theivasanthi, M. Thiruppathi, M. Swaminathan, T. Akomolafe, A. B. Alabi. Photocatalytic degradation of methylene blue by $\mathrm{ZnO} / \mathrm{NiFe}_{2} \mathrm{O}_{4}$ nanoparticles, Appl Surf Sci 455 (2018) 195-200.

[20] F. Davar, A. Majedi, A. Mirzaei. Green synthesis of ZnO Nanoparticles and its Application in the Degradation of some dyes, J. Am. Ceram. Soc 98 (2015) 1739-1746.

[21] T. V. Surendra, S. M. Roopan, M. V. Arasu, N. A. Al-Dhabi, M. Sridharan. Phenolic compounds in drumstick peel for the evaluation of antibacterial, hemolytic and photocatalytic activities, J. Photochem. Photobiol. B: Bio 161 (2016) 463-471.

[22] P. Thatoi, R. Kerry, S. Gouda, G. Das, K. Pramanik, H. Thatoi, J. Patra. Photo-mediated green synthesis of silver and zinc oxide nanoparticles using aqueous extracts of two mangrove plant species, Heritiera fomes and Sonneratia apetala and investigation of their biomedical applications, J. Photochem. Photobiol. B: Bio 163 (2016) 311-318.

[23] R. Javed, M. Usman, S. Tabassum, M. Zia. Effect of capping agents: Structural, optical and biological properties of ZnO nanoparticles, Appl Surf Sci 386 (2016) 319-326.

[24] M. V. Arasua, A. Madankumarb, J. Theerthagiric, S. Sallad, S. Prabub. Synthesis and characterization of $\mathrm{ZnO}$ nanoflakes anchored carbon nanoplates for antioxidant and anticancer activity in MCF7 cell lines, Mater Sci \& Engineer C 102 (2019) 536-540.

[25] G. Sharmila, M. Thirumarimurugan, C. Muthukumaran. Green synthesis of ZnO nanoparticles using Tecoma castanifolia leaf extract: Characterization and evaluation of its antioxidant, bactericidal and anticancer activities, Microchem J 145 (2019) 578-587. 
[26] R. S. Ray, B. Sarma, M. Misra. Random shaped ZnO supported on a porous substrate as supercapacitor, Mater Lett 155 (2015) 102-105.

[27] D. Ponnamma, John-John Cabibihan, M. Rajan, S. Sundar Pethaiah, K. Deshmukh, J. P. Gogoi, S. K. Khadheer Pasha, M. Basheer Ahamed, J. Krishnegowda, B. N. Chandrashekar, A. Reddy Plu, Chun Cheng. Synthesis, optimization and applications of $\mathrm{ZnO} /$ Polymer nanocomposites, Mater Sci \& Engineer C 98 (2019) 1210-1240.

[28] H. Raj Pant, Bishweshwar Pant, H. Joo Kim, A. Amarjargal, C. Hee Park, L. D. Tijing, E. Kyo Kim, C. Sang Kim. A green and facile one-pot synthesis of Ag-ZnO/RGO nanocomposite with effective photocatalytic activity for removal of organic pollutants, Ceram Inter 39 (2013) $5083-5091$.

[29] I. Y. Y. Bu, R. Huang. One-pot synthesis of $\mathrm{ZnO} /$ reduced graphene oxide nanocomposite for supercapacitor applications, Mater Sci semiconduct process 31 (2015) 131-138.

[30] Y. Haldoria, W. Voit, Jae-Jin Shim. Nano ZnO@ reduced graphene oxide composite for high performances supercapacitor: green synthesis in supercritical fluid, Electrochim Acta 120 (2014) 65-72.

[31] J. Jayachandiran, J. Yesuraj, M. Arivanandhan, A. Raja, S. A. Suthanthiraraj, R. Jayavel, D. Nedumaran. Synthesis and Electrochemical Studies of $\mathrm{rGO} / \mathrm{ZnO}$ Nanocomposite for Supercapacitor Application, J Inorg Organomet Polym Mater 28 (2018) 2046-2055.

[32] K. Elumalai, S. Velmurugan. Green synthesis, characterization and antimicrobial activities of zinc oxide nanoparticles from the leaf extract of Azadirachta indica (L.), Appl Surf Sci 345 (2015) 329-336.

[33] R. Dobrucka, J. Długaszewska. Biosynthesis and antibacterial activity of $\mathrm{ZnO}$ nanoparticles using Trifolium pratense flower extract, Saudi J. Biol. Sci 23 (2016) 517-523. 
[34] K. Elumalai, S. Velmurugan, S. Ravi, V. Kathiravan, S. Ashokkumar. Green synthesis of zinc oxide nanoparticles using Moringa oleifera leaf extract and evaluation of its antimicrobial activity, Spectrochim Acta - Part A: Mol and Biomol Spectrosc 143 (2015) 158-164.

[35] A. A. Barzinjy, H. H. Azeez. Green synthesis and characterization of zinc oxide nanoparticles using Eucalyptus globulus Labill. leaf extract and zinc nitrate hexahydrate salt, SN Appl Sci 2 (2020) 1-14.

[36] R. Ramanarayanan, N. M. Bhabhina, M. V. Dharsana, C. V. Nivedita, S. Sindhu. Green synthesis of zinc oxide nanoparticles using extract of Averrhoa bilimbi(L) and their photoelectrode applications, Mater Today: Proceed 5 (2018) 16472-16477.

[37] T. Karnan, S. A. S. Selvakumar. Biosynthesis of $\mathrm{ZnO}$ nanoparticles using rambutan (Nephelium lappaceumL.) peel extract and their photocatalytic activity on methyl orange dye, J. Molecul Struc 1125 (2016) 358-365.

[38] H. Abdul Salam, R. Sivaraj, R. Venckatesh. Green synthesis and characterization of zinc oxide nanoparticles from Ocimum basilicum L. var. purpurascens Benth-Lamiaceae leaf extract, Mater Lett 131 (2014) 16-18.

[39] S. Alamdari, M. Ghamsari, C. Lee, W. Han, H. Park, M. J. Tafreshi, H. Afarideh, M. H. Ara. Preparation and characterization of zinc oxide nanoparticles using leaf extract of sambucus ebulus, Appl Sci 10 (2020) 1-19.

[40] H. Chandra, D. Patel, P. Kumari, J. S. Jangwan, S. Yadav. Phyto-mediated synthesis of zinc oxide nanoparticles of Berberis aristata: Characterization, antioxidant activity and antibacterial activity with special reference to urinary tract pathogens, Mater Sci and Engineer C 102 (2019) 212-220. 
[41] M. Sundrarajan, S. Ambika, K. Bharathi. Plant-extract mediated synthesis of ZnO nanoparticles using Pongamia pinnata and their activity against pathogenic bacteria, Adv Powder Technol 26 (2015) 1294-1299.

[42] A. Diallo, B. D. Ngom, E. Park, M. Maaza. Green synthesis of ZnO nanoparticles by Aspalathus linearis: Structural \& optical properties, J. Alloy Compd 646 (2015) 425-430.

[43] M. Silambarasan, S. Saravanan, T. Soga. Raman and photoluminescence studies of Ag and Fe-doped ZnO nanoparticles, Int. J. ChemTech Res 7 (2015) 1644-1650.

[44] A. Erazo, S. Mosquera, J. E. Rodríguez-Paéz. Synthesis of ZnO nanoparticles with different morphology: Study of their antifungal effect on strains of Aspergillus niger and Botrytis cinerea, Mater. Chem and Phys 234 (2019) 172-184.

[45] M. S. Geetha, H. Nagabhushana, H. N. Shivananjaiah. Green mediated synthesis and characterization of $\mathrm{ZnO}$ nanoparticles using Euphorbia Jatropa latex as reducing agent, J. Sci: Adv Mater and Dev 1 (2016) 301-310.

[46] R. Pandimurugan, S. Thambidurai. Novel seaweed capped ZnO nanoparticles for effective dye photodegradation and antibacterial activity, Adv Powder Technol 27 (2016) 1062-1072.

[47] D. Sharma, M. Sabela, S. Kanchi, P Mdluli, G. Singh, T. A. Stenström, K. Bisetty. Biosynthesis of $\mathrm{ZnO}$ nanoparticles using Jacaranda mimosifolia flowers extract: Synergistic antibacterial activity and molecular simulated facet specific adsorption studies, J. Photochem. Photobiol. B: Bio 162 (2016) 199-207.

[48] N. S. Pavithra, K. Lingaraju, G. K. Raghu, G. Nagaraju. Citrus maxima (Pomelo) juice mediated eco-friendly synthesis of $\mathrm{ZnO}$ nanoparticles: Applications to photocatalytic, electrochemical sensor and antibacterial activities, Spectrochim Acta - Part A: Mol and Biomol Spectrosc 185 (2017) 11-19. 
[49] P. P. Mahamuni, P. M. Patil, M. J. Dhanavade, M. V. Badiger, P. G. Shadija, A. C. Lokhande, R. A. Bohara. Synthesis and characterization of zinc oxide nanoparticles by using polyol chemistry for their antimicrobial and antibiofilm activity. Biochem and Biophy Rep 17 (2019) 71-80.

\section{FIGURE CAPTIONS}

Fig. 1. (a) UV-Vis absorption spectra of Leonotis nepetifolia flower extract and $\mathrm{ZnO}$ nanoparticles Inset shows a plot of $(\mathrm{h} v)$ versus $(\alpha \mathrm{h} v)^{2}$ of $\mathrm{ZnO}$ nanoparticles (b) FTIR spectrum of Leonotis nepetifolia flower extract and ZnO NPs (c) XRD pattern of green synthesized ZnO NPs (d) Raman spectrum of green synthesized ZnO NPs.

Fig. 2. (a) Particle size analysis of $\mathrm{ZnO}$ nanoparticles (b) TGA/DSC of green synthesized $\mathrm{ZnO}$ NPs.

Fig. 3. (a) SEM image of $\mathrm{ZnO}$ nanoparticles and the percentage by weight of each element, of the sample (b) TEM image of $\mathrm{ZnO}$ nanoparticles.

Fig. 4. (a) Photocatalytic activity of synthesized ZnO NPs from the leaves of Leonotis nepetifolia and inset image shows a plot of $-\ln \left(\mathrm{C} / \mathrm{C}_{0}\right)$ versus $\mathrm{t}$ of $\mathrm{ZnO}$ nanoparticles (b) Time profile of MB dye degradation efficiency $(\eta)$.

Fig. 5. (a) Haemolysis $\%$ of positive '+ve' (Titron $X-100)$ and negative '-ve' control (PBS)

(b) Haemolysis \% of untreated RBCs and optimized sample at various $\mathrm{ZnO}$ NPs concentrations

(c) Nitric oxide radical scavenging activity of ascorbic acid, L. nepetifolia flower extract, and $\mathrm{ZnO}$ NPs (d) $\mathrm{H}_{2} \mathrm{O}_{2}$ radical scavenging activity of ascorbic acid, L. nepetifolia flower extract, and $\mathrm{ZnO}$ NPs (e) DPPH radical scavenging activity of ascorbic acid, L. nepetifolia flower extract, and $\mathrm{ZnO}$ NPs. 
Fig. 6. (a) $\mathrm{CV}$ curves of $\mathrm{rGO}-\mathrm{ZnO}$ nanocomposite and $\mathrm{rGO}$ at a scan rate of $50 \mathrm{mV} \mathrm{s}^{-1}$ (b) $\mathrm{CV}$ curves of ZnO-rGO based supercapacitor at different scan rates (c) Sc's of rGO-ZnO nanocomposite and rGO calculated at different scan rates.

Fig. 7. (a) GCD curves of rGO-ZnO nanocomposite and $\mathrm{rGO}$ at $1 \mathrm{Ag}^{-1}$, (b) GCD curves of rGO-ZnO nanocomposite at different current densities, (c) Sc's of rGO-ZnO nanocomposite and rGO at different current densities, and (d) Ragone plots of rGO-ZnO nanocomposite and rGO.

Fig. 8. (a) Nyquist plots of rGO and ZnO-rGO nanocomposites (b) Specific capacitances versus the cycle number of rGO and $\mathrm{ZnO}-\mathrm{rGO}$ nanocomposites at a current density of $10 \mathrm{Ag}^{-1}$. 
Fig.1
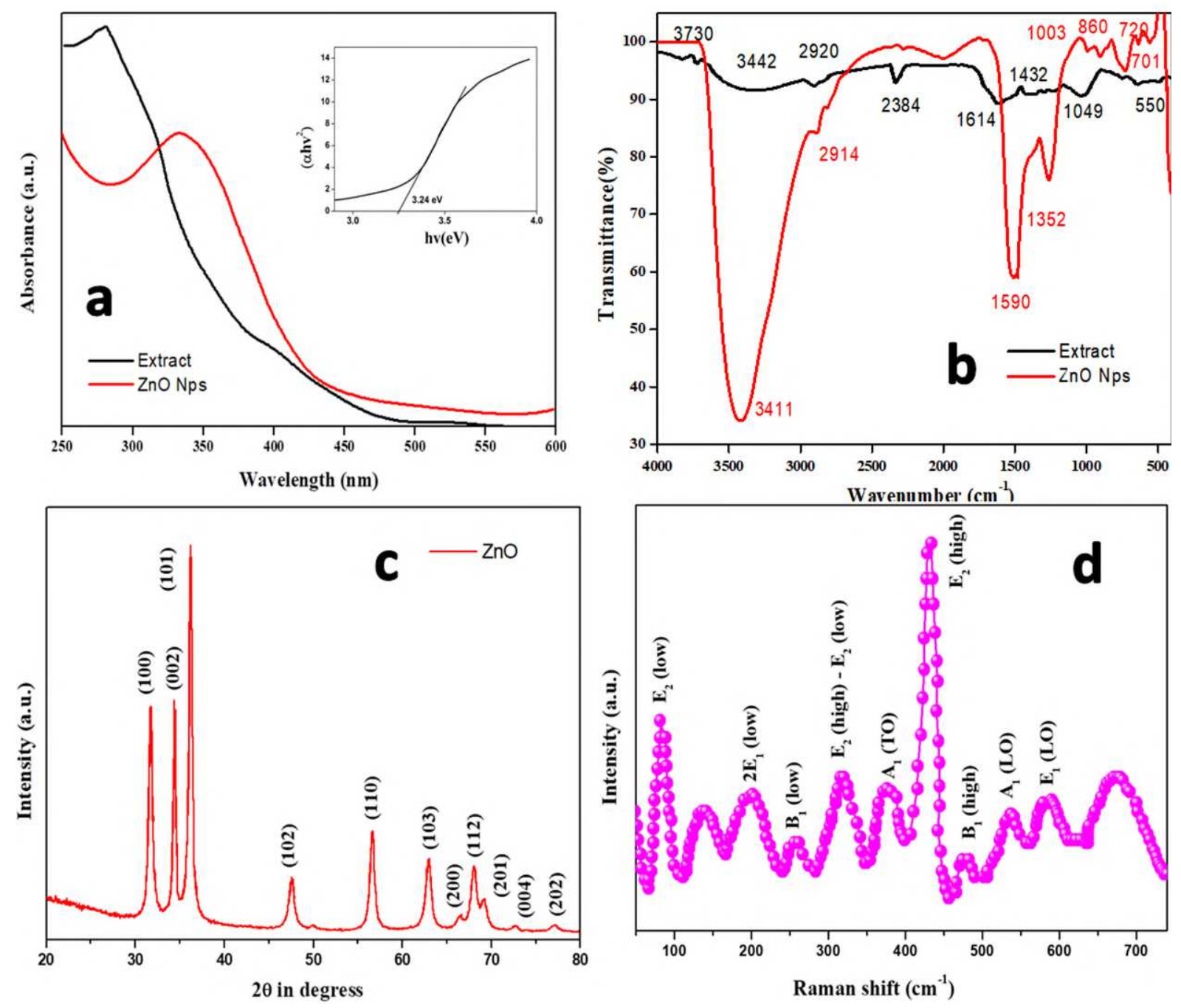

Fig. 1. (a) UV-Vis absorption spectra of Leonotis nepetifolia flower extract and $\mathrm{ZnO}$ nanoparticles Inset shows a plot of $(\mathrm{h} v)$ versus $(\alpha \mathrm{h} v)^{2}$ of $\mathrm{ZnO}$ nanoparticles (b) FTIR spectrum of Leonotis nepetifolia flower extract and ZnO NPs (c) XRD pattern of green synthesized ZnO NPs (d) Raman spectrum of green synthesized ZnO NPs. 
Fig.2
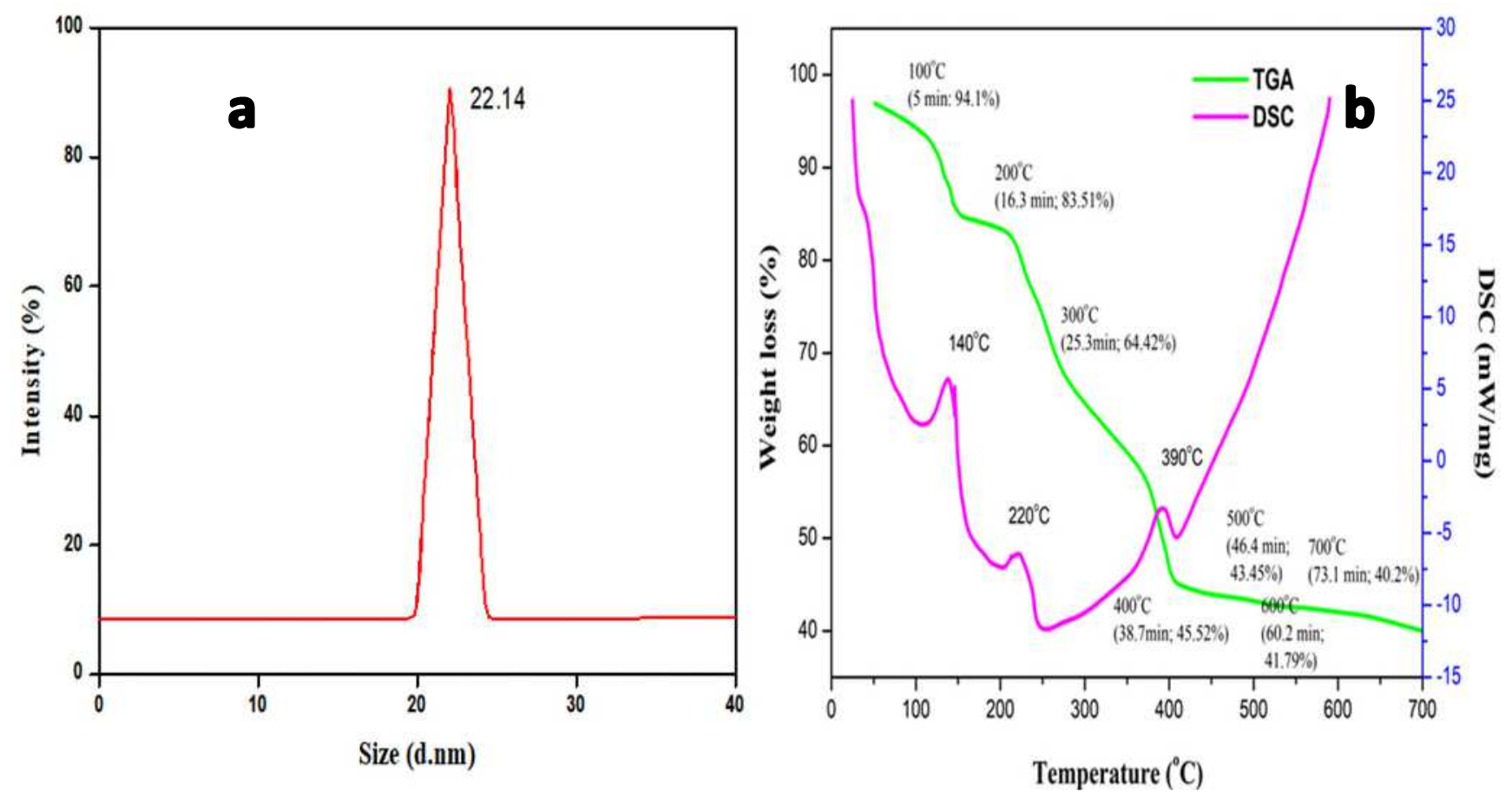

Fig. 2. (a) Particle size analysis of $\mathrm{ZnO}$ nanoparticles (b) TGA/DSC of green synthesized $\mathrm{ZnO}$ NPs. 
Fig.3

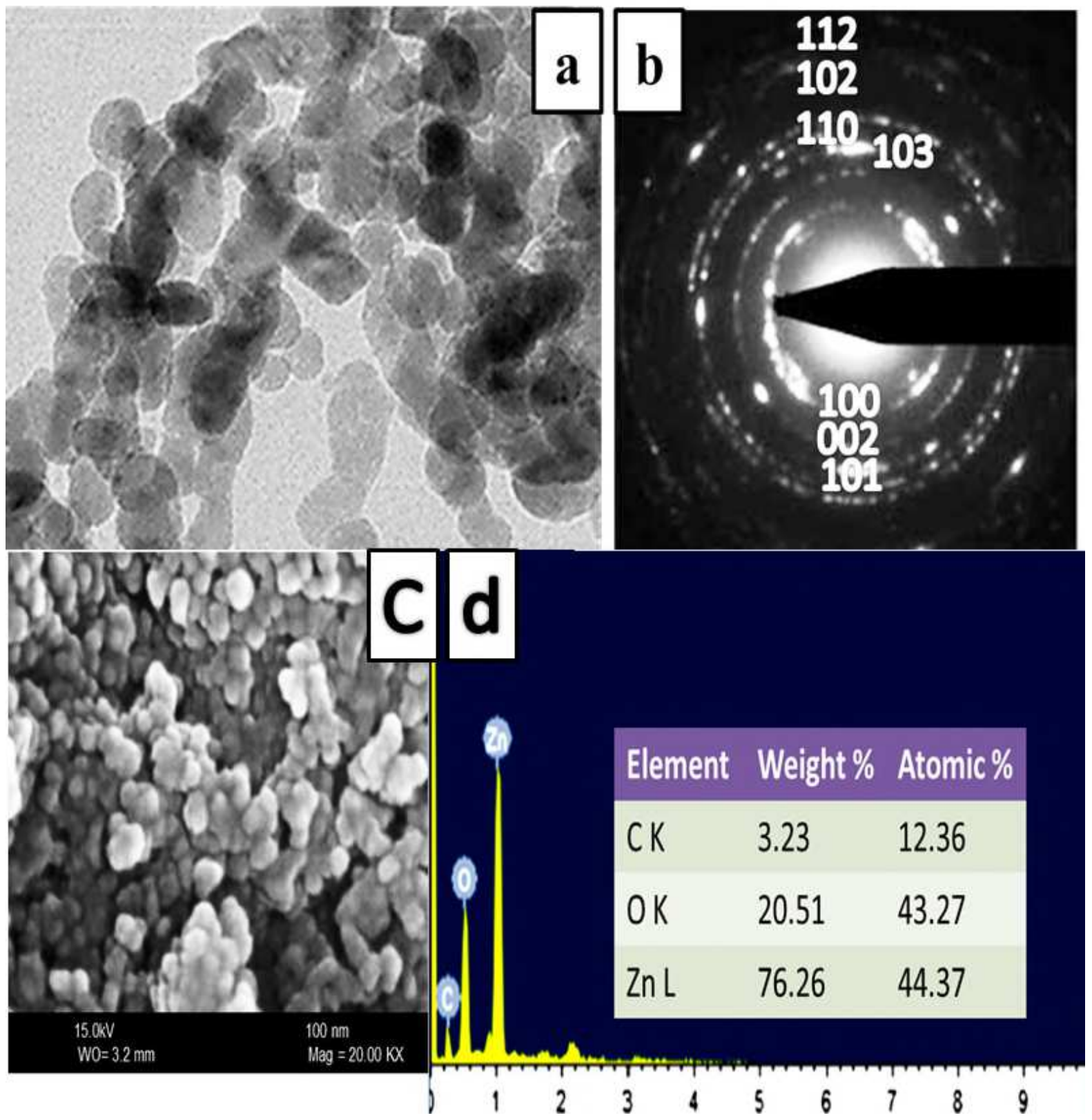

Fig. 3. (a) SEM image of $\mathrm{ZnO}$ nanoparticles and the percentage by weight of each element, of the sample (b) TEM image of $\mathrm{ZnO}$ nanoparticles. 
Fig.4
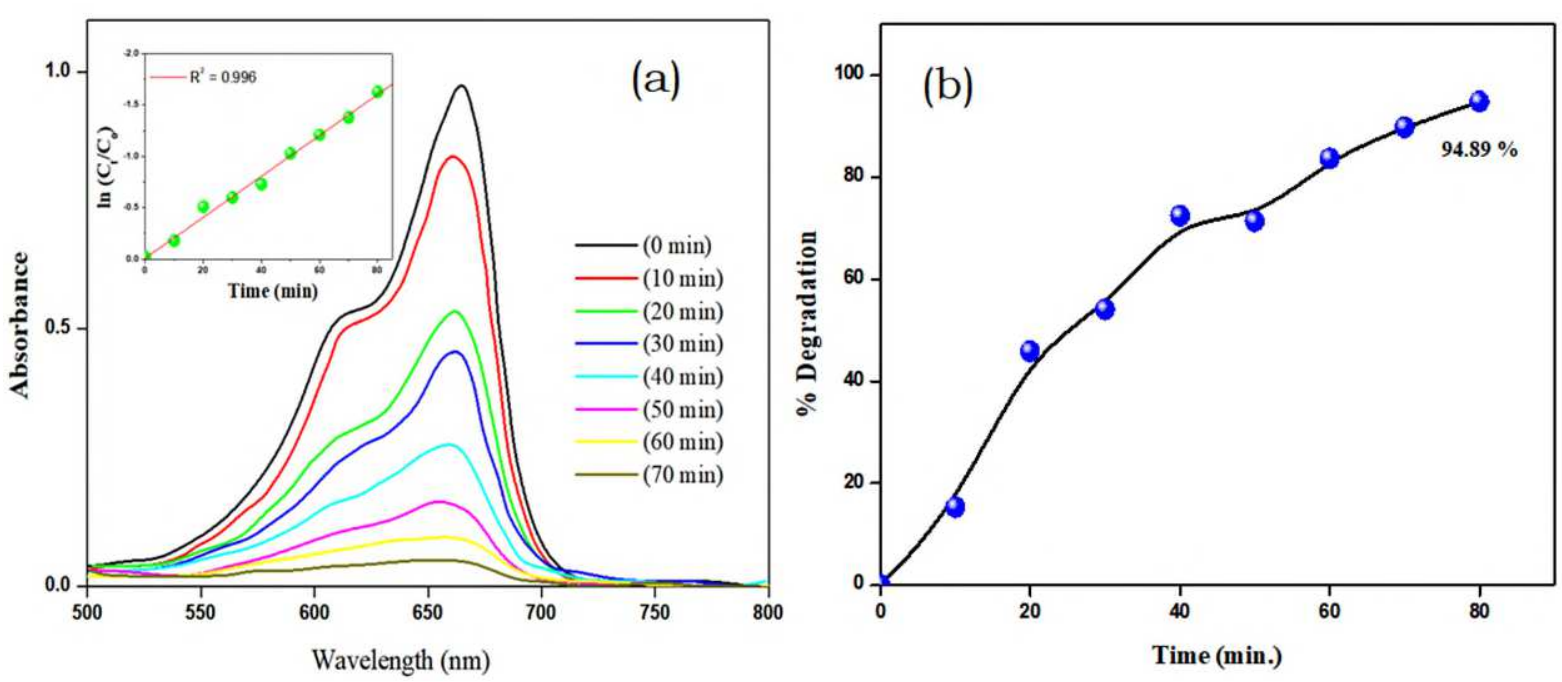

Fig. 4. (a) Photocatalytic activity of synthesized ZnO NPs from the leaves of Leonotis nepetifolia and inset image shows a plot of $-\ln \left(\mathrm{C} / \mathrm{C}_{0}\right)$ versus $\mathrm{t}$ of $\mathrm{ZnO}$ nanoparticles (b) Time profile of MB dye degradation efficiency $(\eta)$. 
Fig. 5
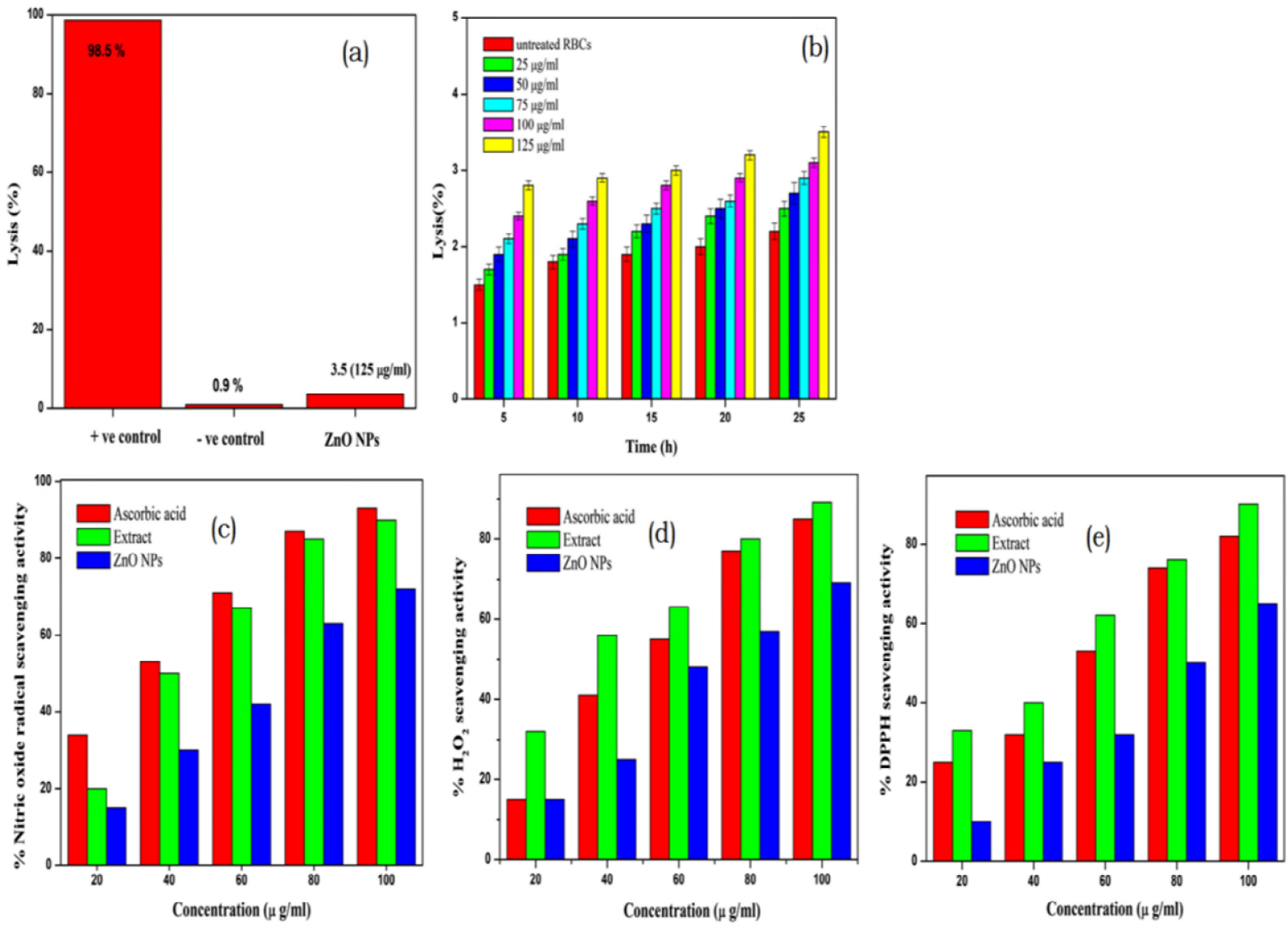

Fig. 5. (a) Haemolysis $\%$ of positive '+ve' (Titron X -100) and negative '-ve' control (PBS)

(b) Haemolysis \% of untreated RBCs and optimized sample at various $\mathrm{ZnO}$ NPs concentrations

(c) Nitric oxide radical scavenging activity of ascorbic acid, L. nepetifolia flower extract, and $\mathrm{ZnO}$ NPs (d) $\mathrm{H}_{2} \mathrm{O}_{2}$ radical scavenging activity of ascorbic acid, L. nepetifolia flower extract, and $\mathrm{ZnO}$ NPs (e) DPPH radical scavenging activity of ascorbic acid, L. nepetifolia flower extract, and $\mathrm{ZnO}$ NPs. 
Fig.6
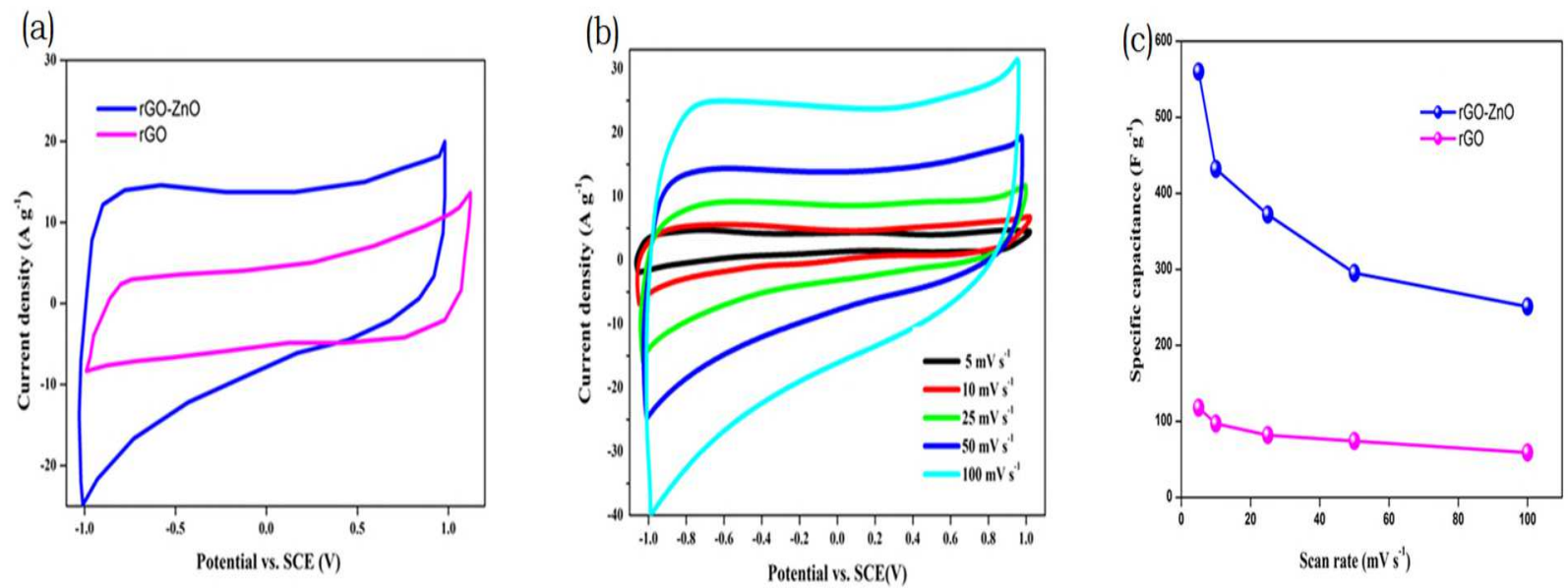

Fig. 6. (a) $\mathrm{CV}$ curves of $\mathrm{rGO}-\mathrm{ZnO}$ nanocomposite and $\mathrm{rGO}$ at a scan rate of $50 \mathrm{mV} \mathrm{s}^{-1}$ (b) $\mathrm{CV}$ curves of ZnO-rGO based supercapacitor at different scan rates (c) Sc's of rGO-ZnO nanocomposite and rGO calculated at different scan rates. 
Fig.7

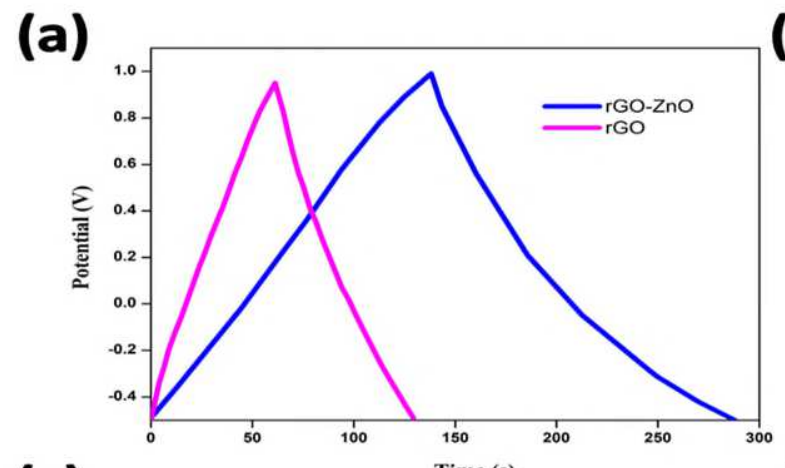

(b)
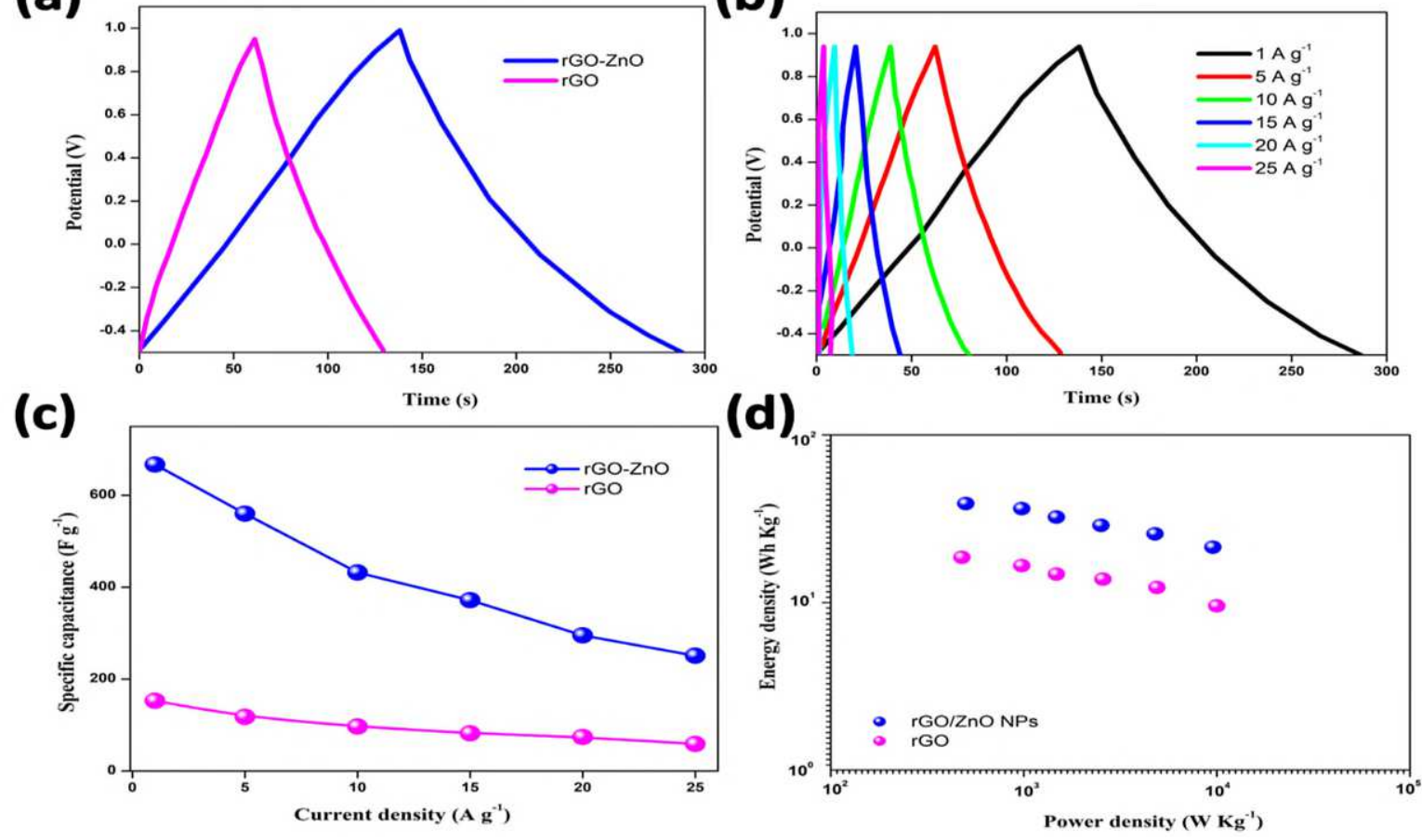

Fig. 7. (a) GCD curves of rGO-ZnO nanocomposite and $\mathrm{rGO}$ at $1 \mathrm{Ag}^{-1}$, (b) GCD curves of rGO-ZnO nanocomposite at different current densities, (c) Sc's of rGO-ZnO nanocomposite and rGO at different current densities, and (d) Ragone plots of rGO-ZnO nanocomposite and rGO. 


\section{Fig.8}
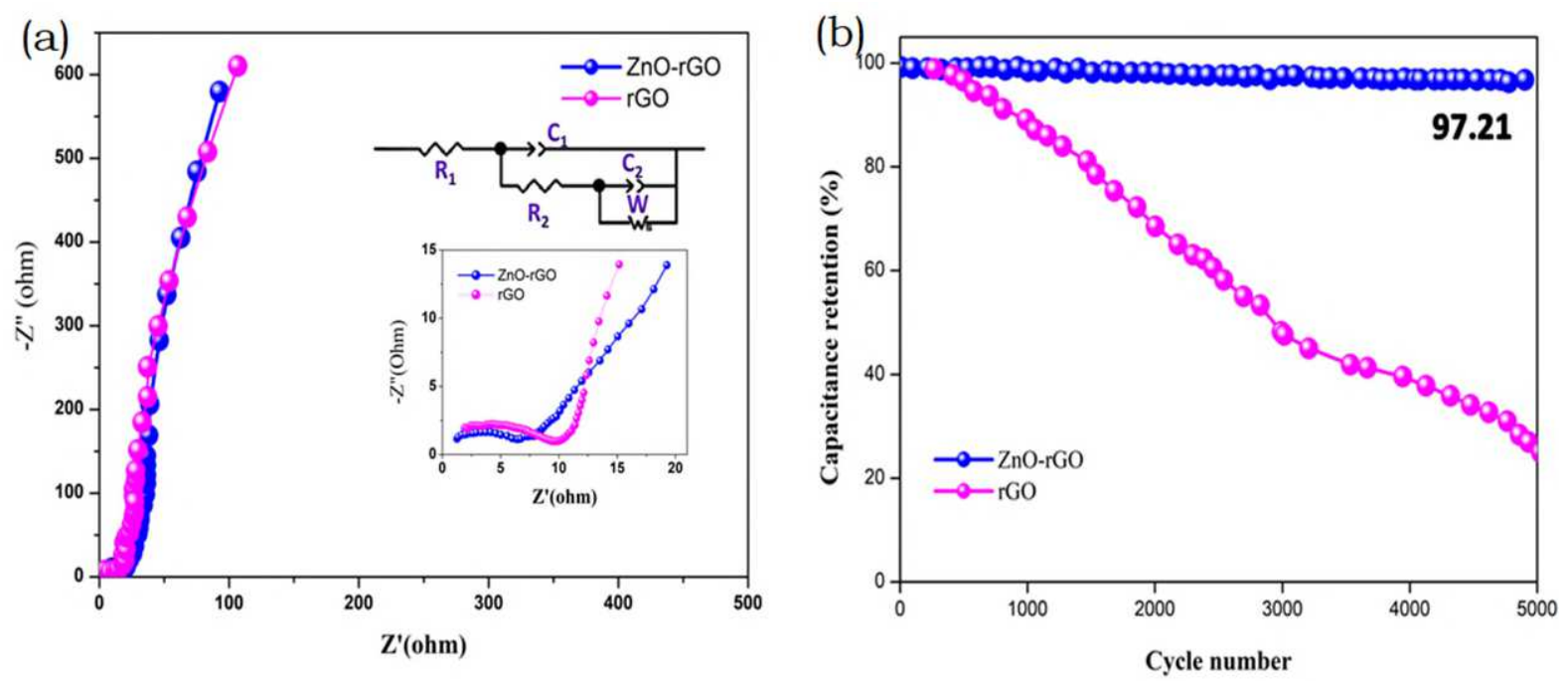

Fig. 8. (a) Nyquist plots of rGO and ZnO-rGO nanocomposites (b) Specific capacitances versus the cycle number of rGO and $\mathrm{ZnO}-\mathrm{rGO}$ nanocomposites at a current density of $10 \mathrm{Ag}^{-1}$. 


\section{TABLE CAPTIONS}

Table 1: Comparison of the specific capacitance of composite electrode material from earlier reports.

\begin{tabular}{|l|l|l|l|}
\hline Material & Electrolyte & $\begin{array}{l}\text { Specific capacitance } \\
\left(\mathrm{F} \mathrm{g}^{-1}\right)\end{array}$ & Reference \\
\hline rGO-ZnO & $1 \mathrm{M} \mathrm{Na}_{2} \mathrm{SO}_{4}$ & 312 & 65 \\
\hline $\mathrm{ZnO}-\mathrm{rGO}$ & $1 \mathrm{M} \mathrm{Na}_{2} \mathrm{SO}_{4}$ & 95 & 66 \\
\hline $\mathrm{ZnO}-\mathrm{rGO}$ & $2 \mathrm{M} \mathrm{KOH}$ & 303 & 67 \\
\hline rGO-ZnO & $6 \mathrm{M} \mathrm{KOH}$ & 122.4 & 68 \\
\hline rGO-ZnO & $2 \mathrm{M} \mathrm{KOH}$ & 667 & This work \\
\hline
\end{tabular}


Graphical Abstract

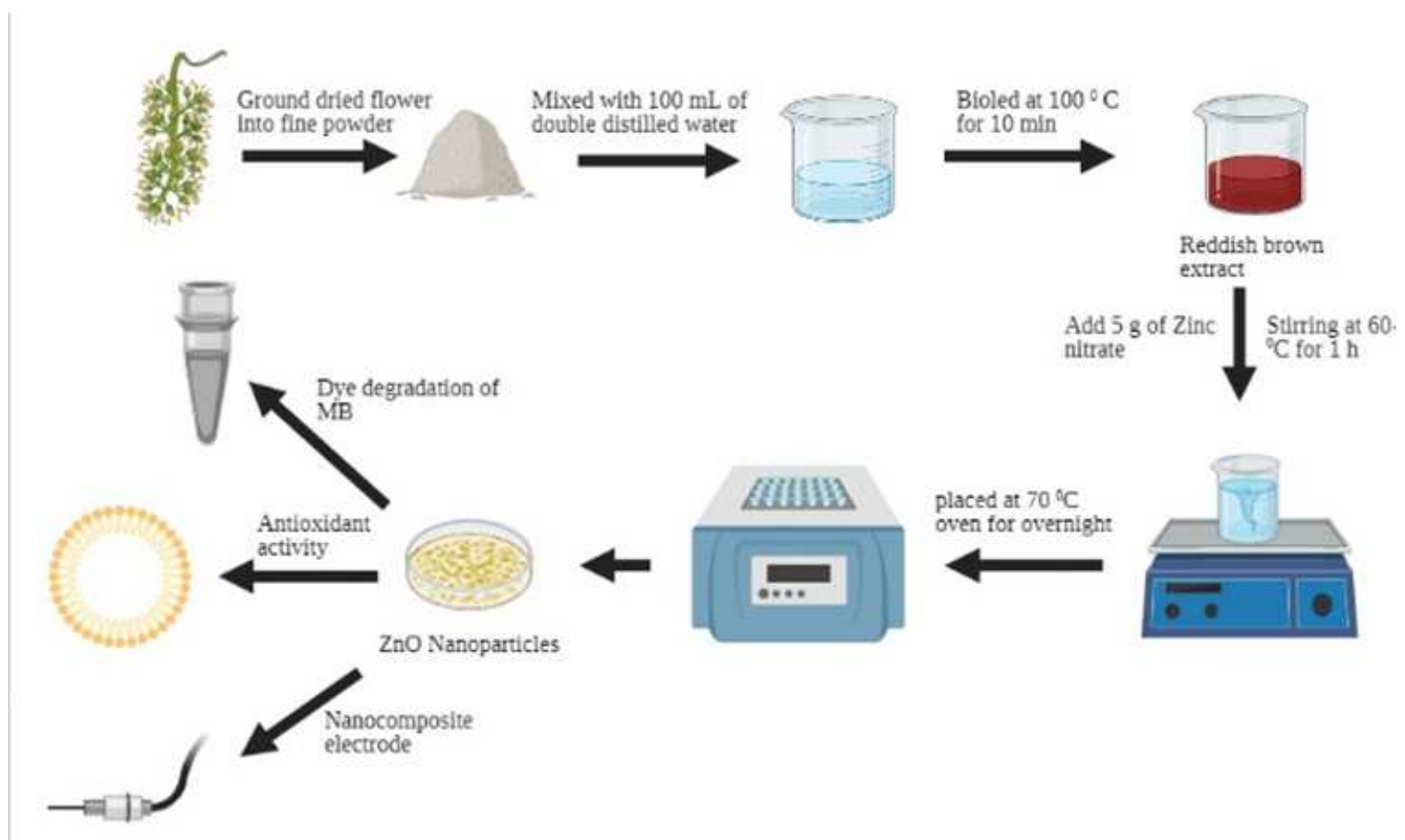



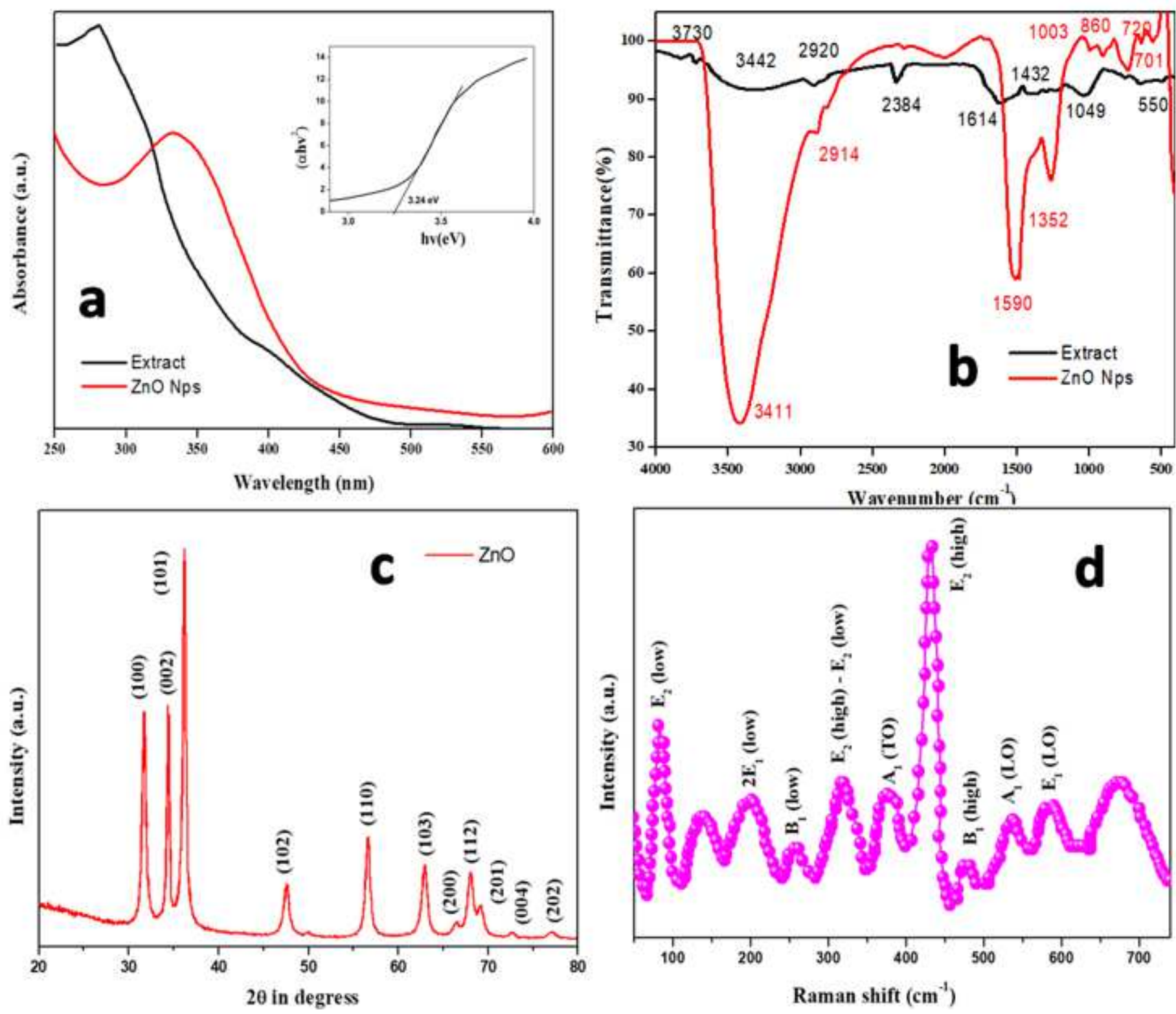

Figure 1

(a) UV-Vis absorption spectra of Leonotis nepetifolia flower extract and ZnO nanoparticles Inset shows a plot of (hv) versus (ahv) 2 of ZnO nanoparticles (b) FTIR spectrum of Leonotis nepetifolia flower extract and ZnO NPs (c) XRD pattern of green synthesized ZnO NPs (d) Raman spectrum of green synthesized ZnO NPs. 

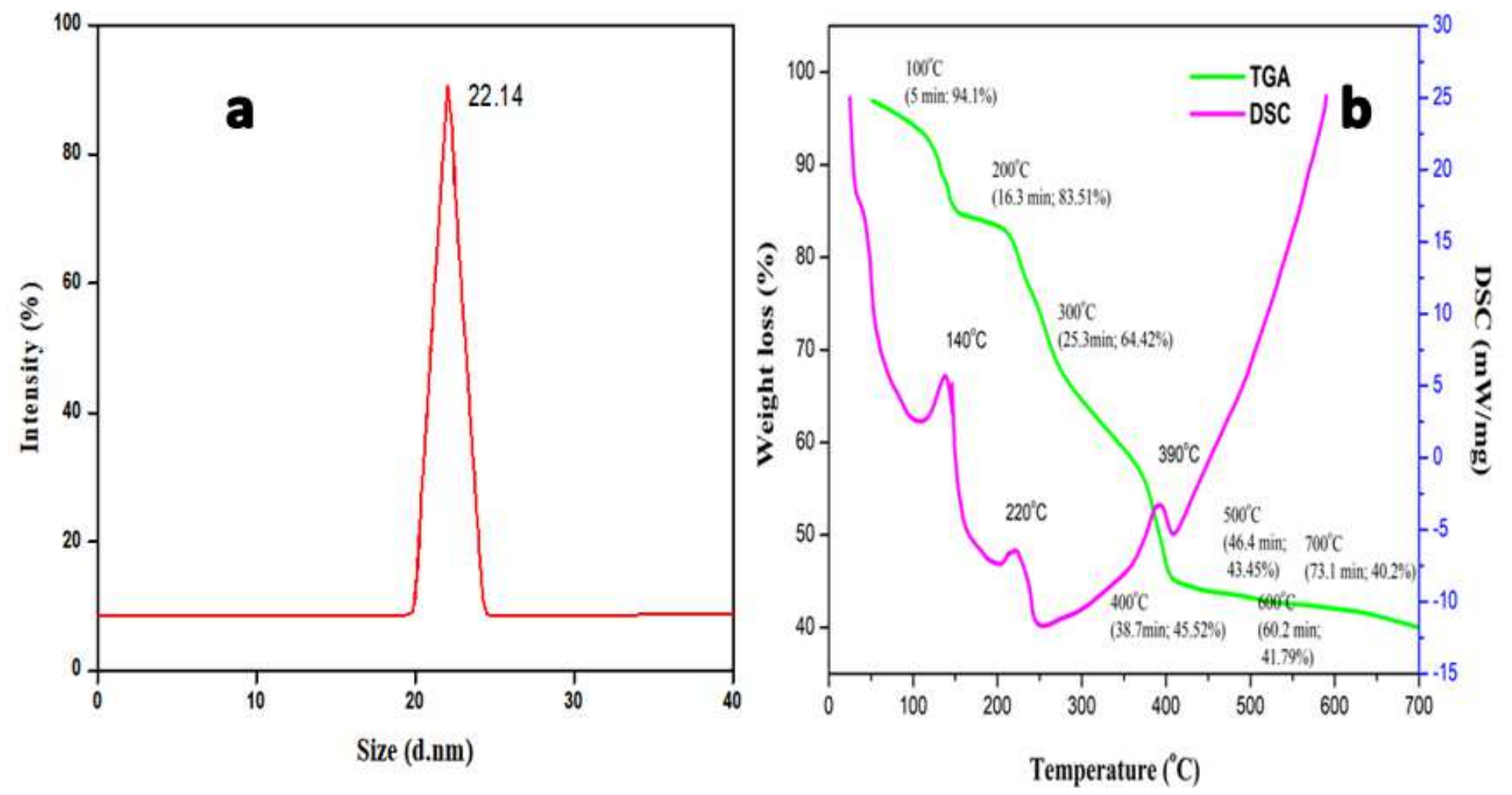

Figure 2

(a) Particle size analysis of ZnO nanoparticles (b) TGA/DSC of green synthesized ZnO NPs. 


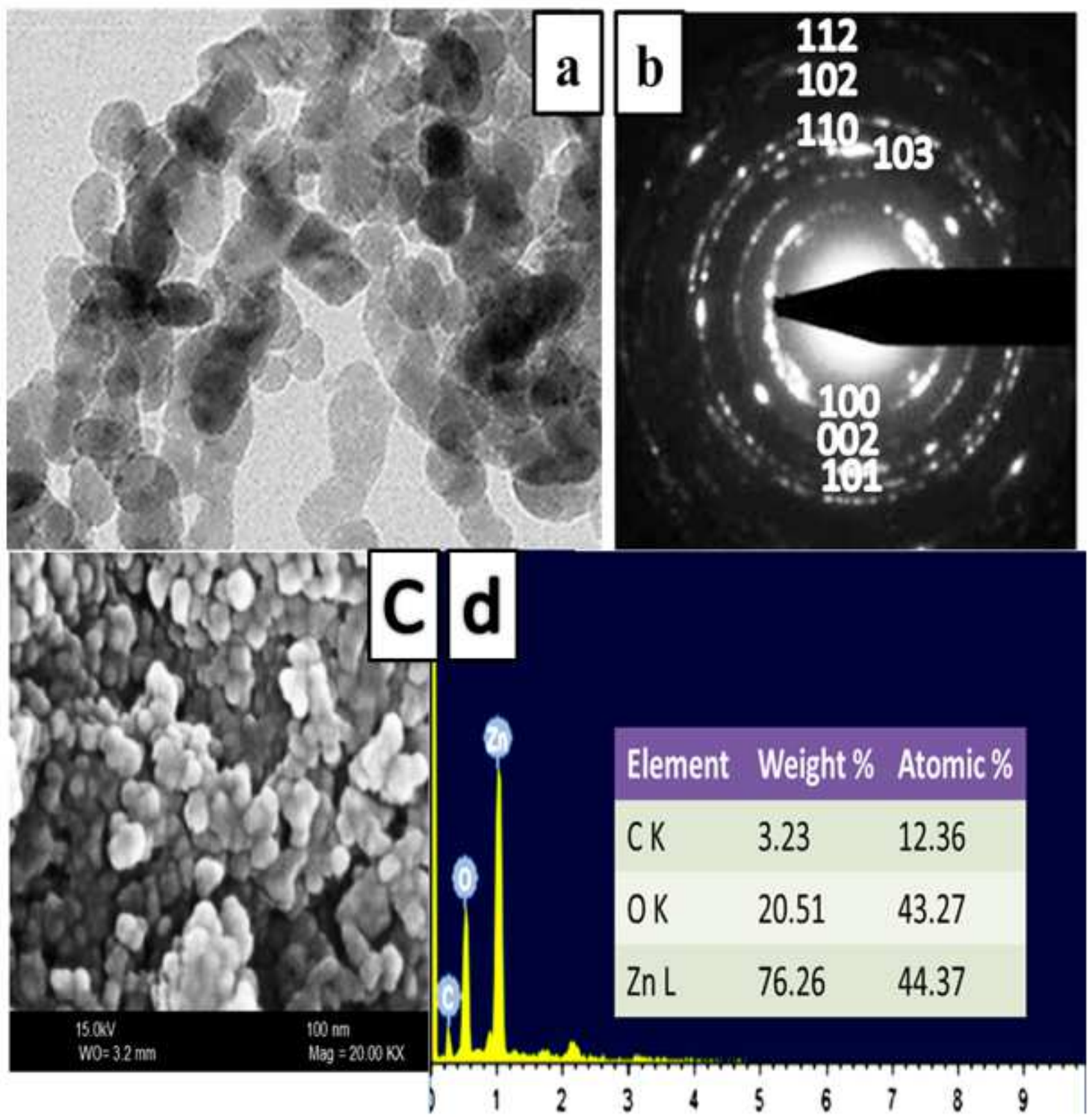

Figure 3

(a) SEM image of ZnO nanoparticles and the percentage by weight of each element, of the sample (b) TEM image of $\mathrm{ZnO}$ nanoparticles. 

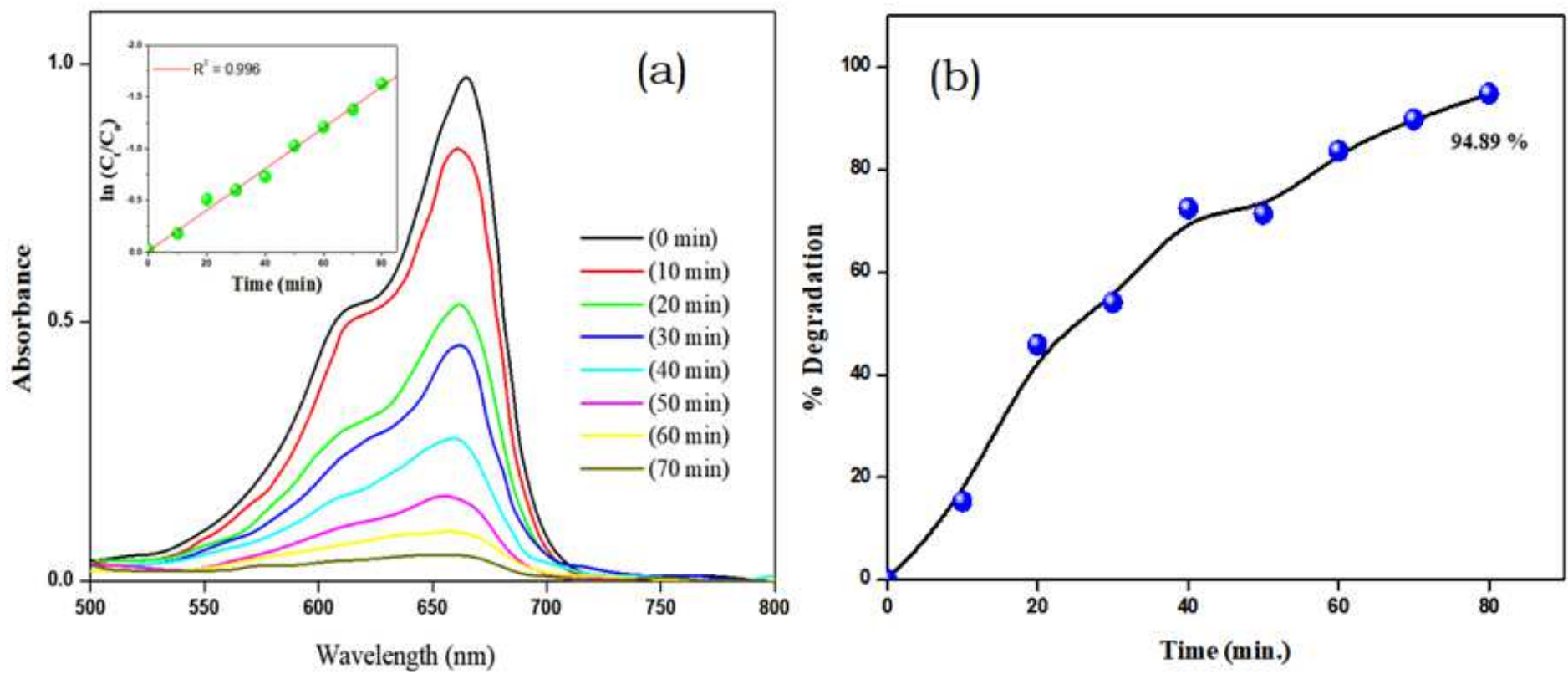

Figure 4

(a) Photocatalytic activity of synthesized ZnO NPs from the leaves of Leonotis nepetifolia and inset image shows a plot of $-\mathrm{In}(\mathrm{C} / \mathrm{CO})$ versus $\mathrm{t}$ of $\mathrm{ZnO}$ nanoparticles (b) Time profile of $\mathrm{MB}$ dye degradation efficiency ( $\eta$ ). 

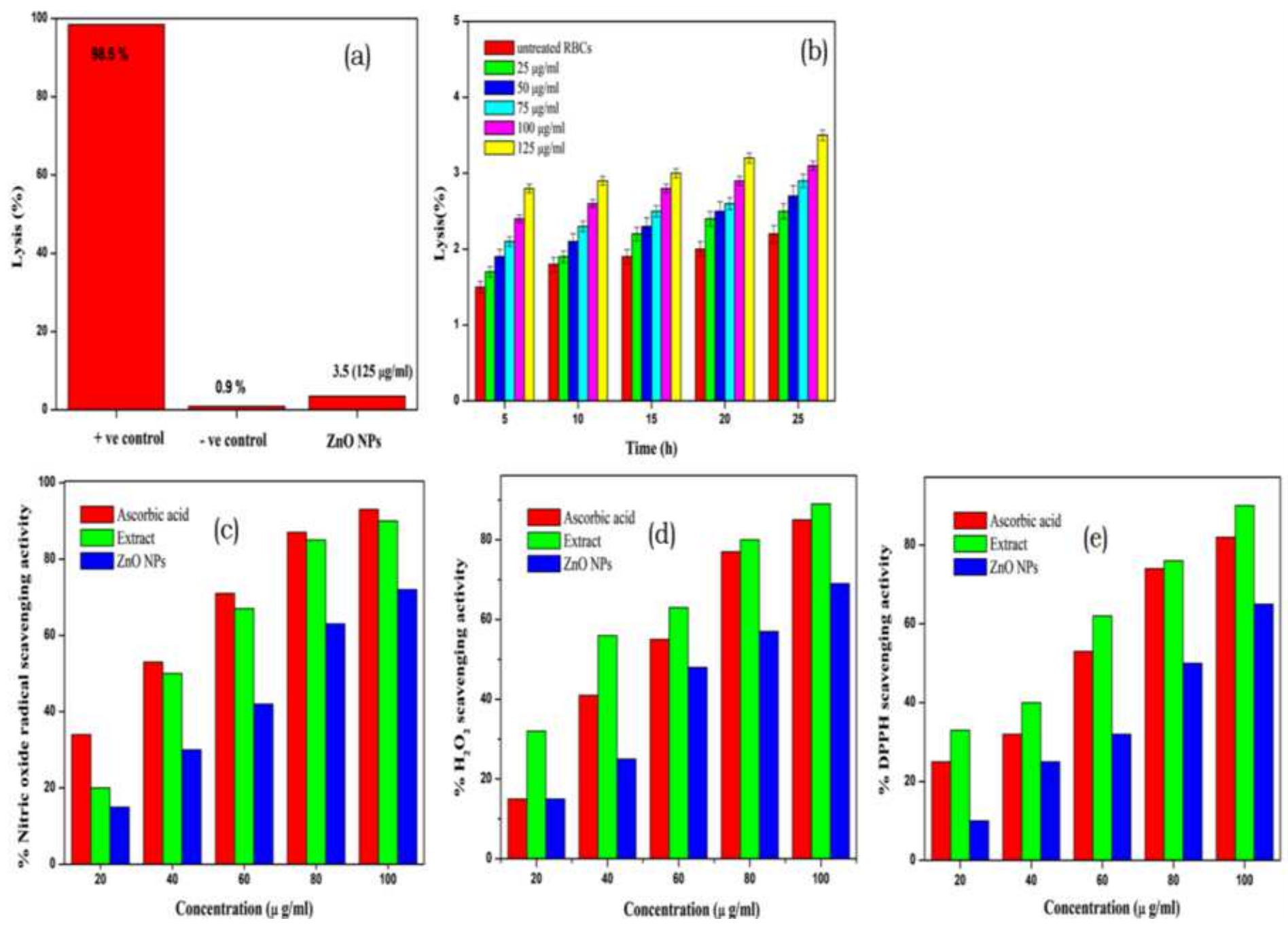

Figure 5

(a) Haemolysis \% of positive '+ve' (Titron X -100) and negative '-ve' control (PBS) (b) Haemolysis \% of untreated RBCs and optimized sample at various ZnO NPs concentrations (c) Nitric oxide radical scavenging activity of ascorbic acid, L. nepetifolia flower extract, and ZnO NPs (d) H2O2 radical scavenging activity of ascorbic acid, L. nepetifolia flower extract, and ZnO NPs (e) DPPH radical scavenging activity of ascorbic acid, L. nepetifolia flower extract, and ZnO NPs. 
(a)

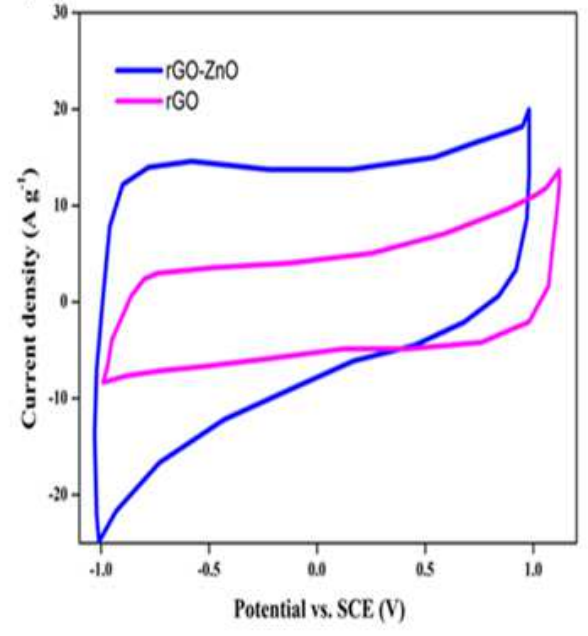

(b)

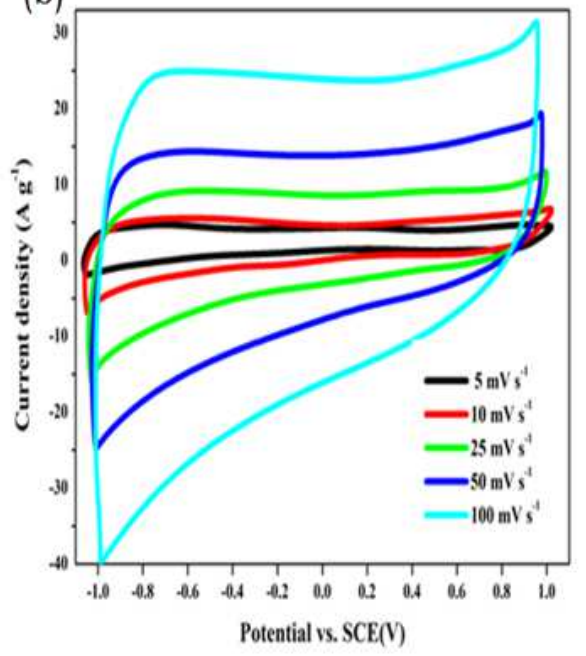

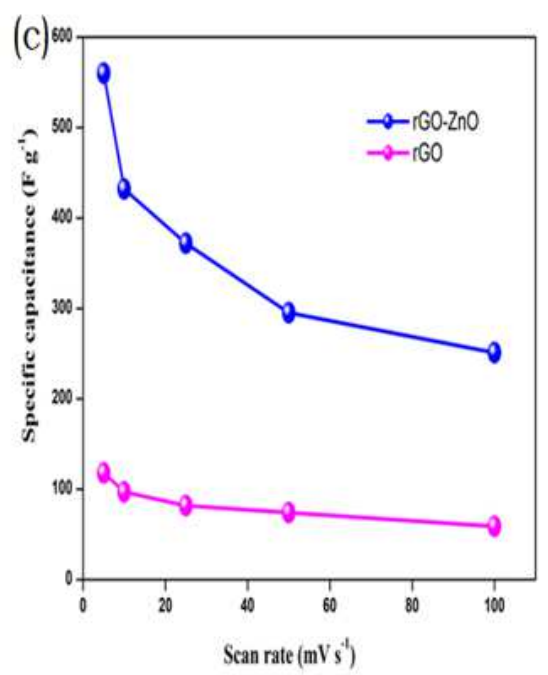

Figure 6

(a) CV curves of rGO-ZnO nanocomposite and rGO at a scan rate of $50 \mathrm{mV}$ s-1 (b) CV curves of ZnO-rGO based supercapacitor at different scan rates (c) Sc's of rGO-ZnO nanocomposite and rGO calculated at different scan rates.

(a)

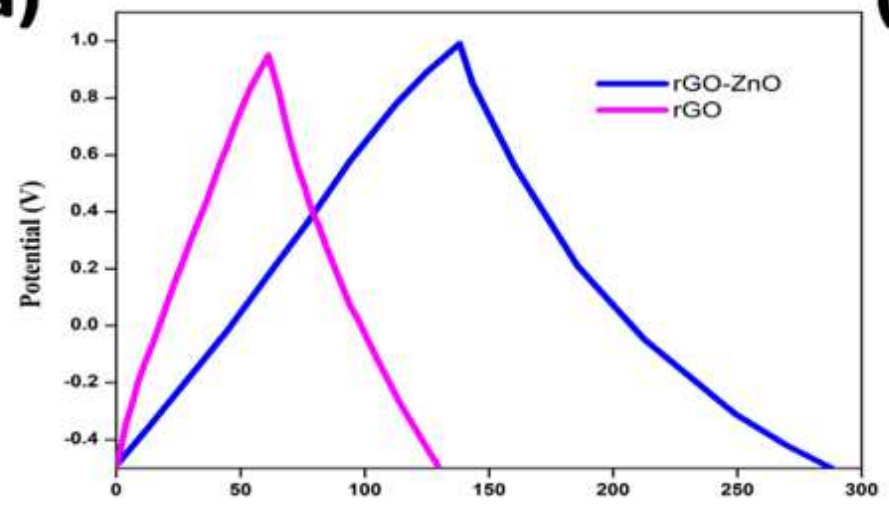

(b)

(c)

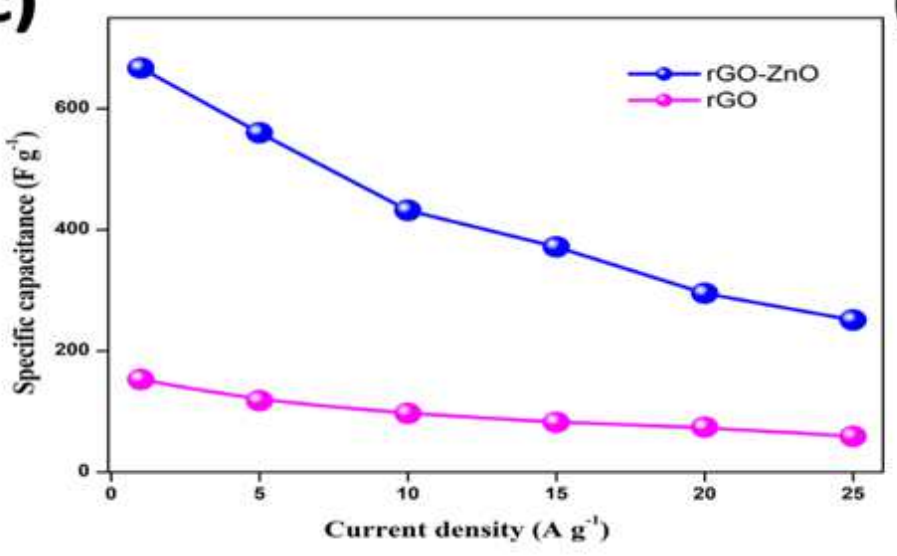

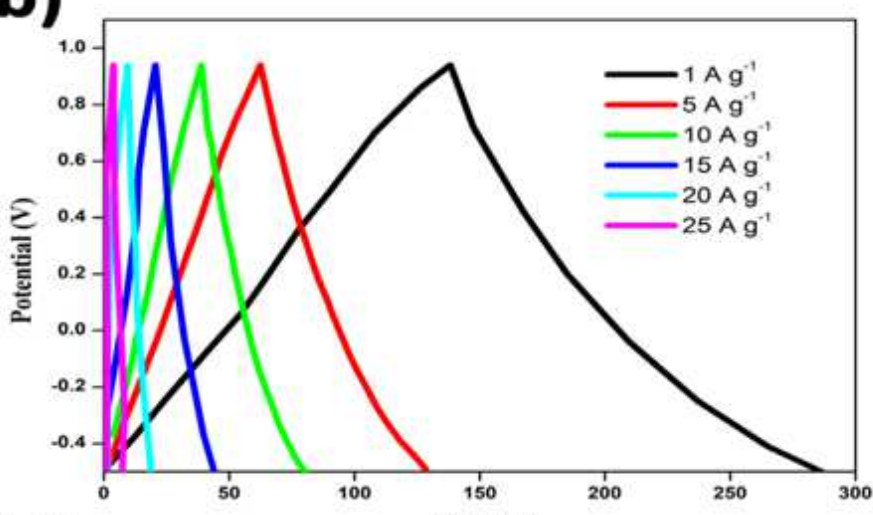

(d)

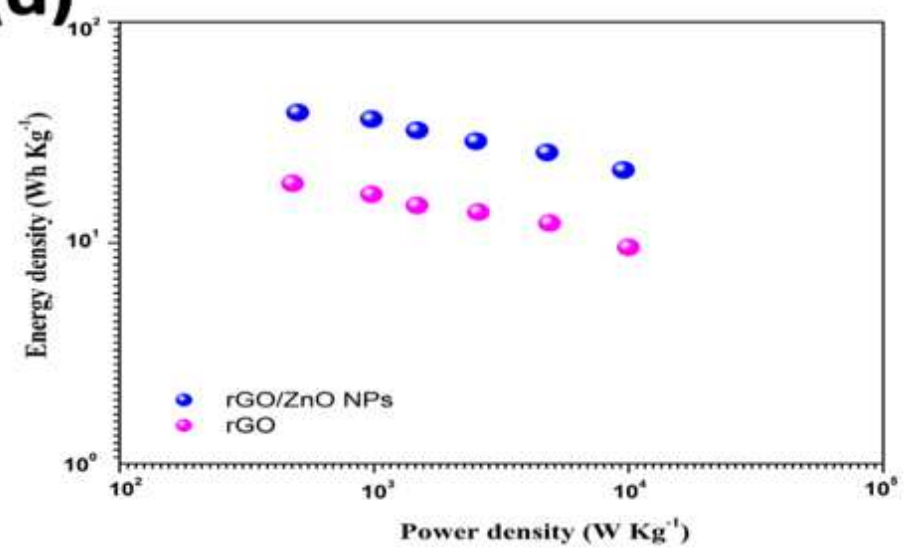

Figure 7 
(a) GCD curves of rGO-ZnO nanocomposite and rGO at $1 \mathrm{Ag}-1$, (b) GCD curves of rGO-ZnO nanocomposite at different current densities, (c) Sc's of rGO-ZnO nanocomposite and rGO at different current densities, and (d) Ragone plots of rGO-ZnO nanocomposite and rGO.
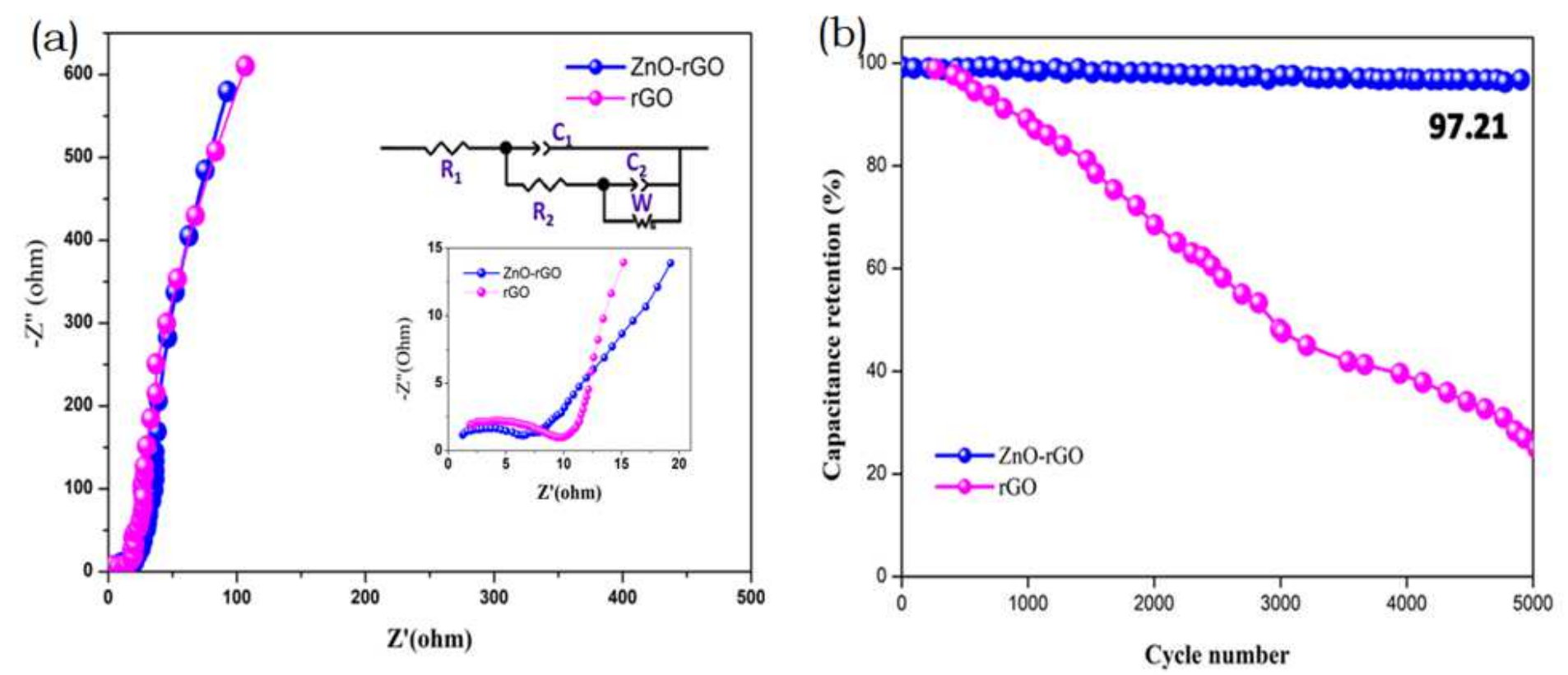

Figure 8

(a) Nyquist plots of rGO and ZnO-rGO nanocomposites (b) Specific capacitances versus the cycle number of rGO and ZnO-rGO nanocomposites at a current density of $10 \mathrm{Ag}-1$.

\section{Supplementary Files}

This is a list of supplementary files associated with this preprint. Click to download.

- GraphicalAbstract.png 